\title{
Final Report for Project TCF-18-15778
}

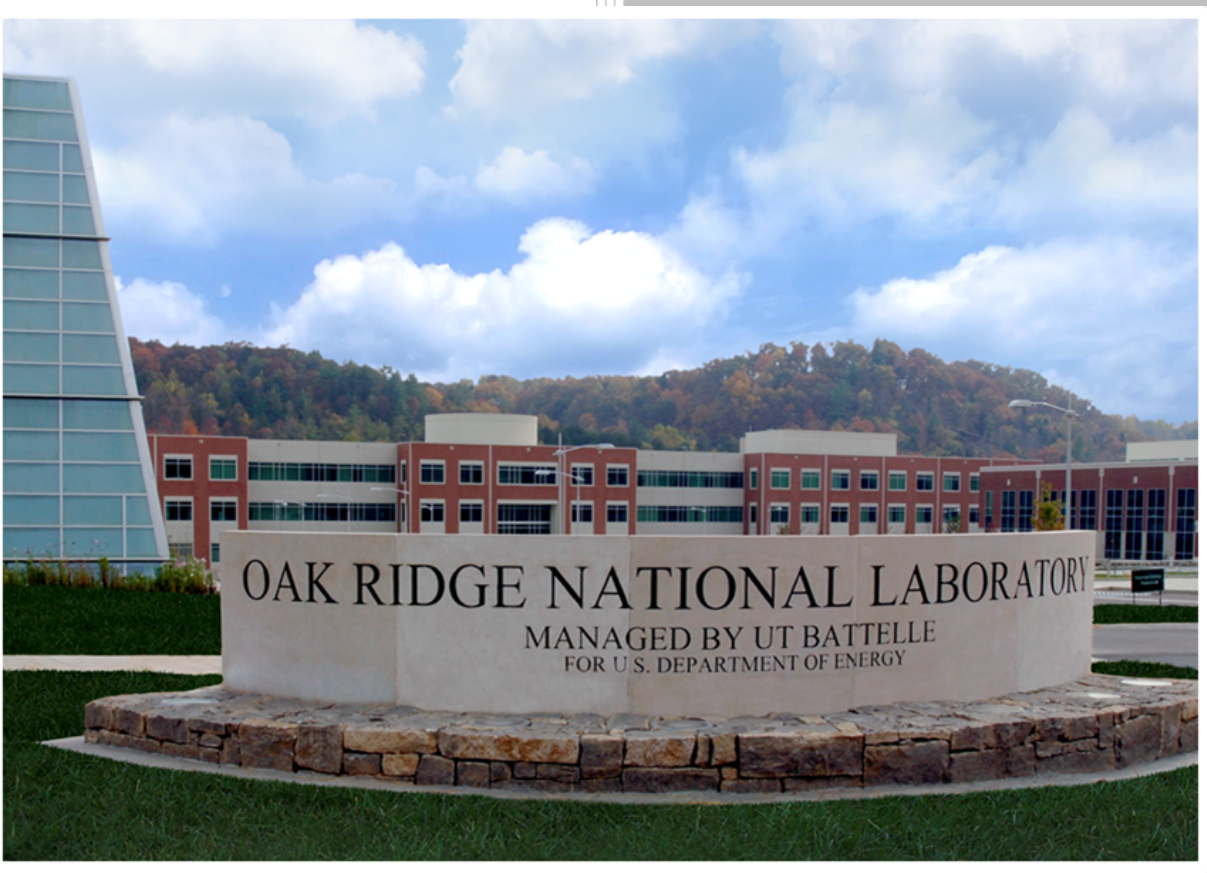

\section{Approved for public release.} Distribution is unlimited.

Santosh Bhatt Kaushik Banerjee

Paul Miller

$09 / 30 / 2020$ 


\section{DOCUMENT AVAILABILITY}

Reports produced after January 1, 1996, are generally available free via US Department of Energy (DOE) SciTech Connect.

Website www.osti.gov

Reports produced before January 1, 1996, may be purchased by members of the public from the following source:

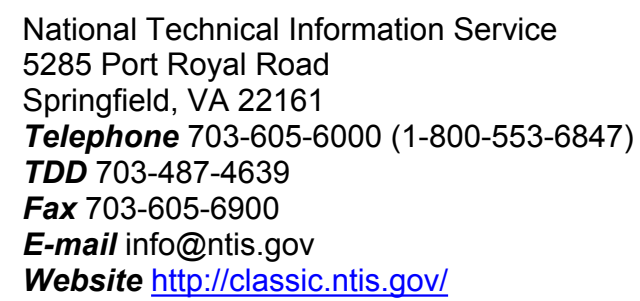

Reports are available to DOE employees, DOE contractors, Energy Technology Data Exchange representatives, and International Nuclear Information System representatives from the following source:

Office of Scientific and Technical Information

PO Box 62

Oak Ridge, TN 37831

Telephone 865-576-8401

Fax 865-576-5728

E-mail reports@osti.gov

Website http://www.osti.gov/contact.html

This report was prepared as an account of work sponsored by an agency of the United States Government. Neither the United States Government nor any agency thereof, nor any of their employees, makes any warranty, express or implied, or assumes any legal liability or responsibility for the accuracy, completeness, or usefulness of any information, apparatus, product, or process disclosed, or represents that its use would not infringe privately owned rights. Reference herein to any specific commercial product, process, or service by trade name, trademark, manufacturer, or otherwise, does not necessarily constitute or imply its endorsement, recommendation, or favoring by the United States Government or any agency thereof. The views and opinions of authors expressed herein do not necessarily state or reflect those of the United States Government or any agency thereof. 
Used (Spent) Nuclear Fuel Management and Analysis Tool

FINAL REPORT FOR PROJECT TCF-18-15778

\author{
Santosh Bhatt \\ Kaushik Banerjee \\ Paul Miller
}

Milestone No. M2TT-18OR060101041

Date Published: 09/30/2020

Prepared by

OAK RIDGE NATIONAL LABORATORY

Oak Ridge, TN 37831-6283

managed by

UT-BATTELLE, LLC

for the

US DEPARTMENT OF ENERGY

under contract DE-AC05-00OR22725 
This page is intentionally left blank. 


\section{CONTENTS}

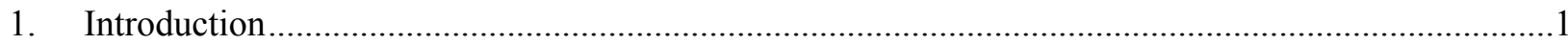

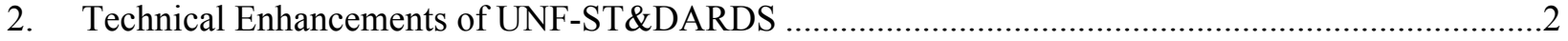

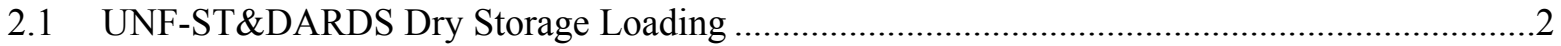

2.1.1 Preparation of Data Required for Dry Storage Loading Optimization Tool...................2

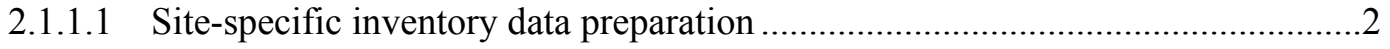

2.1.1.2 Assembly-specific decay heat calculations .....................................................

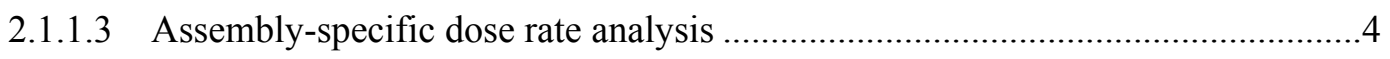

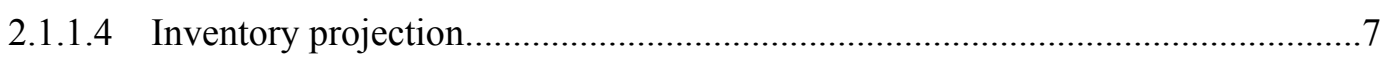

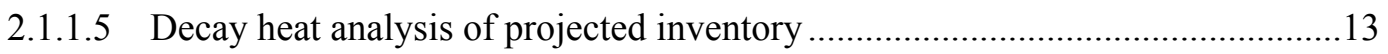

2.2 DRY STORAGE Loading Optimization in UNF-ST\&DARDS ...........................................15

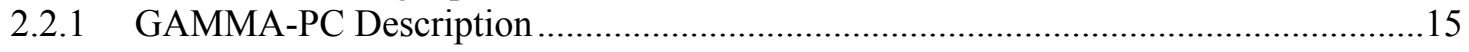

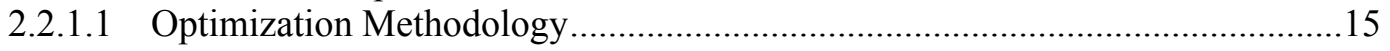

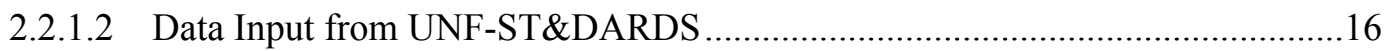

2.2.2 UNF-ST\&DARDS Integration of Optimization Tool ..............................................17

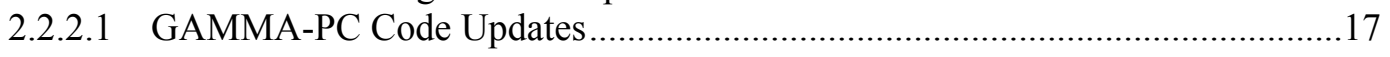

2.2.3 Performing Loading Optimization in UNF-ST\&DARDS .........................................22

2.2.4 Loading Optimization Case Studies and Results .....................................................27

2.2.4.1 Comparisons Among Code Selected Solution Sets ..........................................27

2.2.4.2 Comparison to a Realistic Loading Scenario..................................................... 30

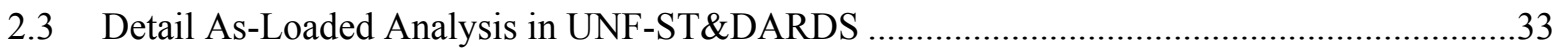

2.4 UNF-ST\&DARDS Initial Coupling with Reactor Core Simulators .........................................33

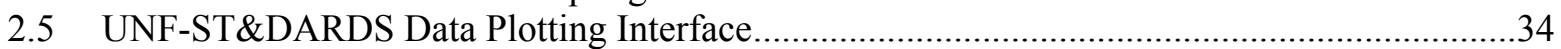

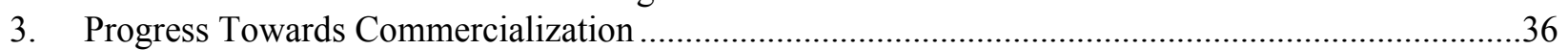

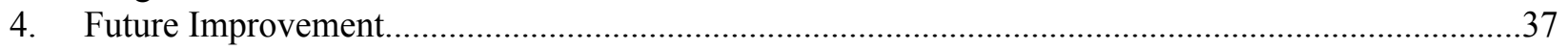

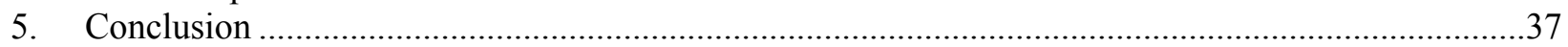

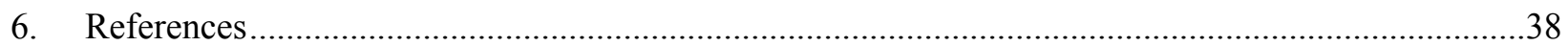




\section{FIGURES}

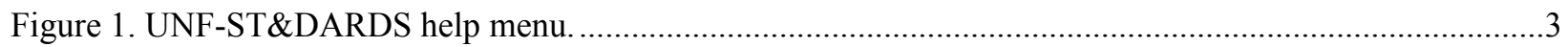

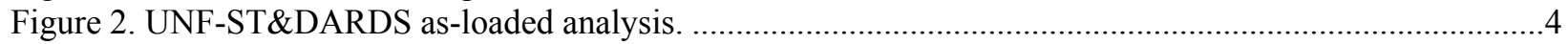

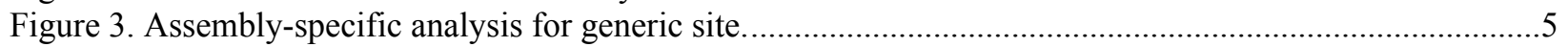

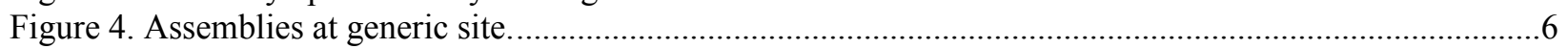

Figure 5. Parameter selection for assembly-specific dose analysis. .........................................................6

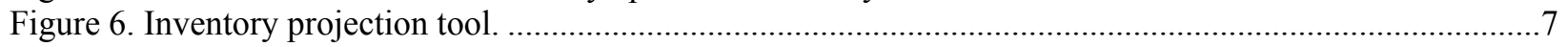

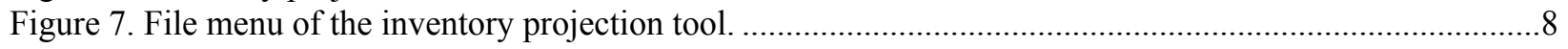

Figure 8. Preference panel of the projection tool showing database credentials. ...............................................

Figure 9. Connect menu option of the inventory projection tool. ................................................................

Figure 10. Reactor information displayed in the startup panel of the projection tool. ......................................10

Figure 11. Case configurations panel of the projection tool. .........................................................................

Figure 12. Add new reactors panel in the projection tool. ...........................................................................11

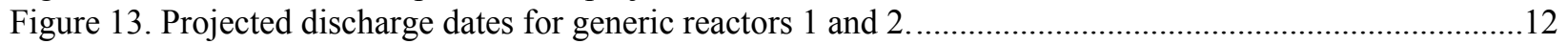

Figure 14. Projected inventory determined by the projection tool..................................................................12

Figure 15. Projected assembly decay heat analysis in UNF-ST\&DARDS.....................................................13

Figure 16. UNF-ST\&DARDS decay heat analysis for projected inventory as a function of analysis

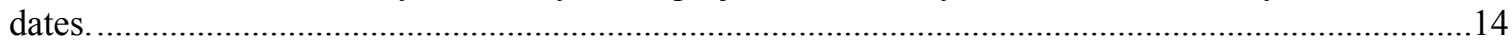

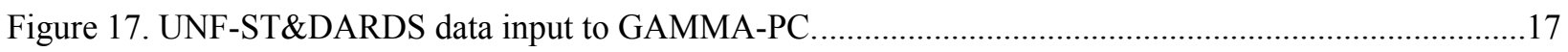

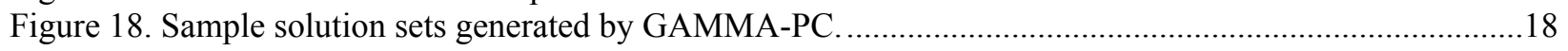

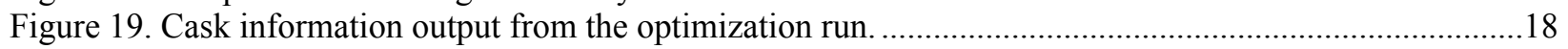

Figure 20. Assembly information for the individual casks. .....................................................................19

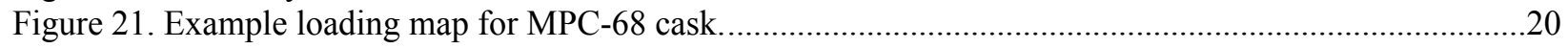

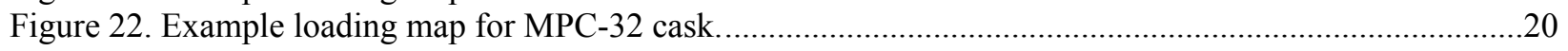

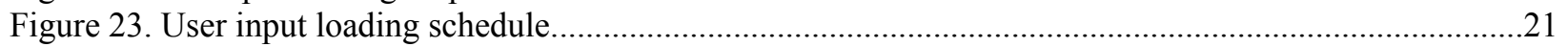

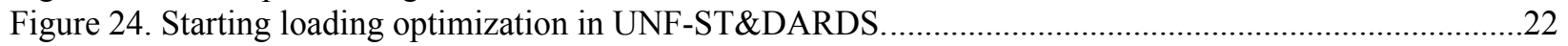

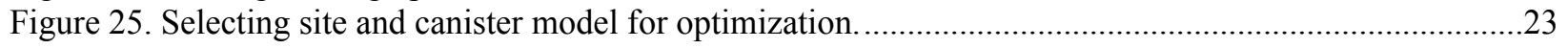

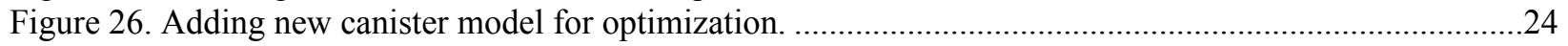

Figure 27. Selecting storage and transport overpack models.........................................................................24

Figure 28. Adding zone loading information to the canister map.................................................................25

Figure 29. Adding cask and overpack information from the database. ...........................................................26

Figure 30. Adding Cask and Overpack Information from the CSV files......................................................27

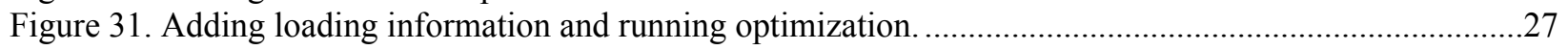

Figure 32. Solutions selected by the optimization tool from the set of solutions. .............................................28

Figure 33. Comparison of optimized and oldest, coldest solutions. .............................................................28

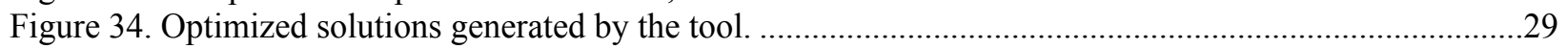

Figure 35. Decay heat distribution of different optimized solutions. ............................................................. 30

Figure 36. Cask number and average decay heat comparison for the Scenarios A and B................................31

Figure 37. Total decay heat comparison for loading Scenarios A and B ....................................................32

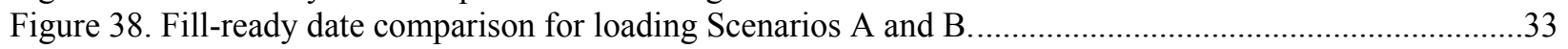

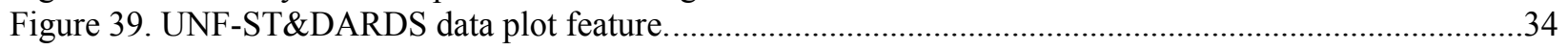

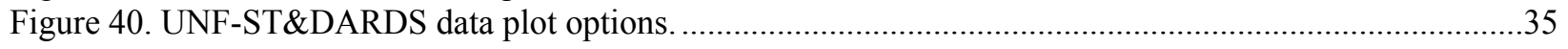

Figure 41. An example plot generated by UNF-ST\&DARDS. ..................................................................... 


\section{ACRONYMS}

$\begin{array}{ll}\text { BWR } & \text { boiling water reactor } \\ \text { CFR } & \text { Code of Federal Regulations } \\ \text { CoC } & \text { certificate of compliance } \\ \text { DOE } & \text { US Department of Energy } \\ \text { EPRI } & \text { Electric Power Research Institute } \\ \text { GIS } & \text { geographic information system } \\ \text { GRASP } & \text { greedy randomized adaptive search procedure } \\ \text { GUI } & \text { graphical user interface } \\ \text { ISF } & \text { interim storage facility } \\ \text { ISFSI } & \text { independent spent fuel installation } \\ \text { NE } & \text { Office of Nuclear Energy } \\ \text { NRC } & \text { US Nuclear Regulatory Commission } \\ \text { ORNL } & \text { Oak Ridge National Laboratory } \\ \text { OTT } & \text { Office of Technology Transitions } \\ \text { PWR } & \text { pressurized water reactor } \\ \text { RSICC } & \text { Radiation Safety Information Computational Center } \\ \text { SKB } & \text { Swedish Nuclear Fuel and Waste Management Co. } \\ \text { SQL } & \text { structured query language } \\ \text { TCF } & \text { Technology Commercialization Fund } \\ \text { TRL } & \text { technology readiness level } \\ \text { UNF } & \text { used nuclear fuel } \\ \text { UNF-ST\&DARDS } & \text { Used Nuclear Fuel-Storage, Transportation \& Disposal Analysis Resource and } \\ & \text { Data System }\end{array}$




\begin{abstract}
This report documents work performed under the Technology Commercialization Fund (TCF-18-15778, Used [spent] Nuclear Fuel Management and Analysis Tool) award provided by the US Department of Energy (DOE) Office of Technology Transitions (OTT). This report describes various Used Nuclear Fuel - Storage, Transportation \& Disposal Analysis Resource and Data System (UNF-ST\&DARDS) enhancements to advance the technology readiness level (TRL). The Phase I technology commercialization funding (TCF) provided by DOE OTT has been instrumental in advancing UNF-ST\&DARDS technology.

The principal work performed under TCF is the integration of the initial dry storage loading optimization algorithm into UNF-ST\&DARDS. The TCF also supports various other software enhancements, as well as interaction with commercial nuclear industries over the past two years. At the time of the TCF award, the UNF-ST\&DARDS software version was 3.1 Beta. Version 3.1 also received a certificate of registration from the US Copyright Office. The current publicly available UNF-ST\&DARDS version is 4.0, and the current internal development UNF-ST\&DARDS version is 4.0.3 Beta. The UNF-

ST\&DARDS team is planning to release the principal enhancements performed under TCF as a part of version 4.1, which is currently scheduled to be released in December 2020.
\end{abstract}




\section{INTRODUCTION}

This report documents work performed under the Technology Commercialization Fund (TCF-18-15778, Used [spent] Nuclear Fuel Management and Analysis Tool) award provided by the US Department of Energy (DOE) Office of Technology Transitions (OTT). This report describes various Used Nuclear Fuel - Storage, Transportation \& Disposal Analysis Resource and Data System (UNF-ST\&DARDS) enhancements to advance the technology readiness level (TRL). The Phase I technology commercialization funding (TCF) provided by DOE OTT has been instrumental in advancing UNF-ST\&DARDS technology.

UNF-ST\&DARDS is a software package that provides used nuclear fuel (UNF) management and analysis capabilities. With no permanent UNF repository currently in the US, the need for long-term UNF management has become a reality. As evidence, the US Nuclear Regulatory Commission (NRC) recently examined the environmental impact of onsite UNF dry-storage for an extended amount of time when developing the Continued Storage Rule [1]. Because of the diverse systems used throughout the world and the large volume of UNF, long-term management of UNF through final disposition is a complex undertaking requiring a variety of data and analysis tools. These tools are essential for realistic, timedependent characterization of UNF and its related systems (e.g., cask systems) to (1) manage UNF during extended storage at the reactor sites, (2) support a successful large-scale transportation campaign (3) plan for, design, and operate interim storage facilities (ISFs), and (4) support eventual geological disposition of UNF. Oak Ridge National Laboratory (ORNL) is developing UNF-ST\&DARDS to manage UNF data, along with several compatible analysis tools for time-dependent characterization of UNF and related systems.

UNF-ST\&DARDS was initially developed as a foundational resource for the DOE Office of Nuclear Energy (NE) as a credible, controlled, centrally managed data source for key information essential to each UNF management area - storage, transportation, and disposal. UNF-ST\&DARDS incorporates a UNF database integrated with nuclear analysis capabilities, enabling automated assembly- and cask-specific analysis, including depletion/decay, criticality, shielding, and thermal analyses. UNF-ST\&DARDS interfaces with the SCALE [2] code system for nuclear analysis. UNF-ST\&DARDS has the unparalleled ability to track UNF through the entire back end of the fuel cycle as currently defined by the once through policy in the US, from the time UNF is discharged from a reactor through its disposal in a geological repository. There is currently no other established tool providing similar UNF data and analysis integration and management capability. UNF-ST\&DARDS has been applied to real-world problems such as determining the feasibility of direct disposal of currently loaded UNF storage systems [3].

Dry casks have been used for over 40 years to store UNF and other related components. The technology was initially licensed with the expectation that utilities would use the dry storage as a temporary solution for less than 20 years before the UNF would be moved to permanent storage [1]. However, due to delays and uncertainties regarding permanent storage, the UNF has largely remained onsite. There are currently over 3,000 commercial UNF loaded casks, with approximately 300 casks being added to that number each year [4]. While most of the UNF remains onsite in dry casks and wet storage, many of the utilities have established independent spent fuel installations (ISFSIs) for onsite dry storage for durations beyond reactor lifetimes and pool closings.

About three-quarter of the UNF inventory is currently in wet storage [5], and the number of the discharged assemblies will grow larger by the time all the current US operating reactors are end operations. The primary focus for utilities storing UNF is to meet the safe and cost-effective immediate storage needs within the licensing regulations. This has led to a wide variety of cask designs for dry storage used in the United States. There are currently 14 active certificates of compliance (CoCs) issued by the NRC under 10 Code of Federal Regulations (CFR) Part 72 [6], of which 8 are storage only modules and 6 are storage and transport modules. A list of all currently active CoCs is provided in [7]. 
Most dry casks have been loaded with storage in mind, making their transportation and long-term storage complicated in the future. The rapidly growing UNF inventory makes it more important to use methods to optimize dry cask loading.

The principal work performed under TCF is the integration of the initial dry storage loading optimization algorithm developed by Spencer [7] into UNF-ST\&DARDS. The TCF also supports various other software enhancements, as well as interaction with commercial nuclear industries over the past two years. At the time of the TCF award, the UNF-ST\&DARDS software version was 3.1 Beta. Version 3.1 also received a certificate of registration from the US Copyright Office. The current publicly available UNFST\&DARDS version is 4.0, and the current internal development UNF-ST\&DARDS version is 4.0.3 Beta. The UNF-ST\&DARDS team is planning to release the principal enhancements performed under TCF as a part of version 4.1, which is currently scheduled to be released in December 2020.

The remainder of this report is organized as follows. Section 2 discusses technical enhancements of various UNF-ST\&DARDS capabilities. Section 3 discusses progress towards commercialization. Section 4 presents future work, and Section 5 provides conclusions and discussion.

\section{TECHNICAL ENHANCEMENTS OF UNF-ST\&DARDS}

This section describes the following background and technical enhancements of UNF-ST\&DARDS: (1) initial dry storage loading tool, (2) detail as-loaded UNF characterization pipeline, (3) initial approach for coupling with reactor core simulators, and (4) initial development of a data visualization and plotting interface.

\subsection{UNF-ST\&DARDS DRY STORAGE LOADING}

This section describes the process of preparing the input data required for dry storage loading, execution of the dry storage loading algorithm with various options, and dry storage loading results.

\subsubsection{Preparation of Data Required for Dry Storage Loading Optimization Tool}

As discussed above, UNF-ST\&DARDS contains a UNF database and uses data from this database for various analyses, including dry storage loading optimization. The UNF-ST\&DARDS released version does not contain reactor-specific inventory, assembly-specific decay heat, projected inventory, or decay heat of projected inventory. The required data to execute the dry storage loading tool includes:

- Site-specific discharge inventory (e.g., assembly ID, discharge burnup, initial enrichment, discharge date)

- Information on assemblies that are already in dry storage systems to exclude them from the loading optimization,

- Assembly-specific decay heat of discharge inventory as a function of time

- Assembly-specific dose rates as a function of time to evaluate overall cask dose limits

- Projected discharge inventory for various projection scenarios, and

- Decay heat of projected discharge inventory

\subsubsection{Site-specific inventory data preparation}

The user of UNF-ST\&DARDS must follow the steps below, strictly in order, to import the site-specific discharge inventory and information of assemblies that are already in dry storage systems.

1. Add a facility.

2. Add spent nuclear fuel pool(s) at that facility.

3. Add reactor(s) at that facility (reactor needs a pool for discharge).

4. Add reactor cycle information. 
5. Add discharge assembly type (e.g., W1717WL). Available assembly types can be found from the assembly type table in the database (right-click, select rows). The database comes with publicly available pressurized water reactor (PWR) and boiling water reactor (BWR) assembly types.

6. Add irradiation parameters for the newly added assembly type

7. Add Discharge assembly information. At this point, all the assemblies will be in the pool

8. Add a dry storage pad using the geographic information system (GIS) in the code, and link that with the facility added in step 1 .

9. Add canisters on the pad.

10. Add canister inventory. This will automatically change the status of the assemblies (loaded in the canister) from wet to dry.

The steps above are also described in detail in the manual that is provided with the software (see "Data Import Using GUI" section of the manual). The manual can be obtained using the help menu as shown in Figure 1.

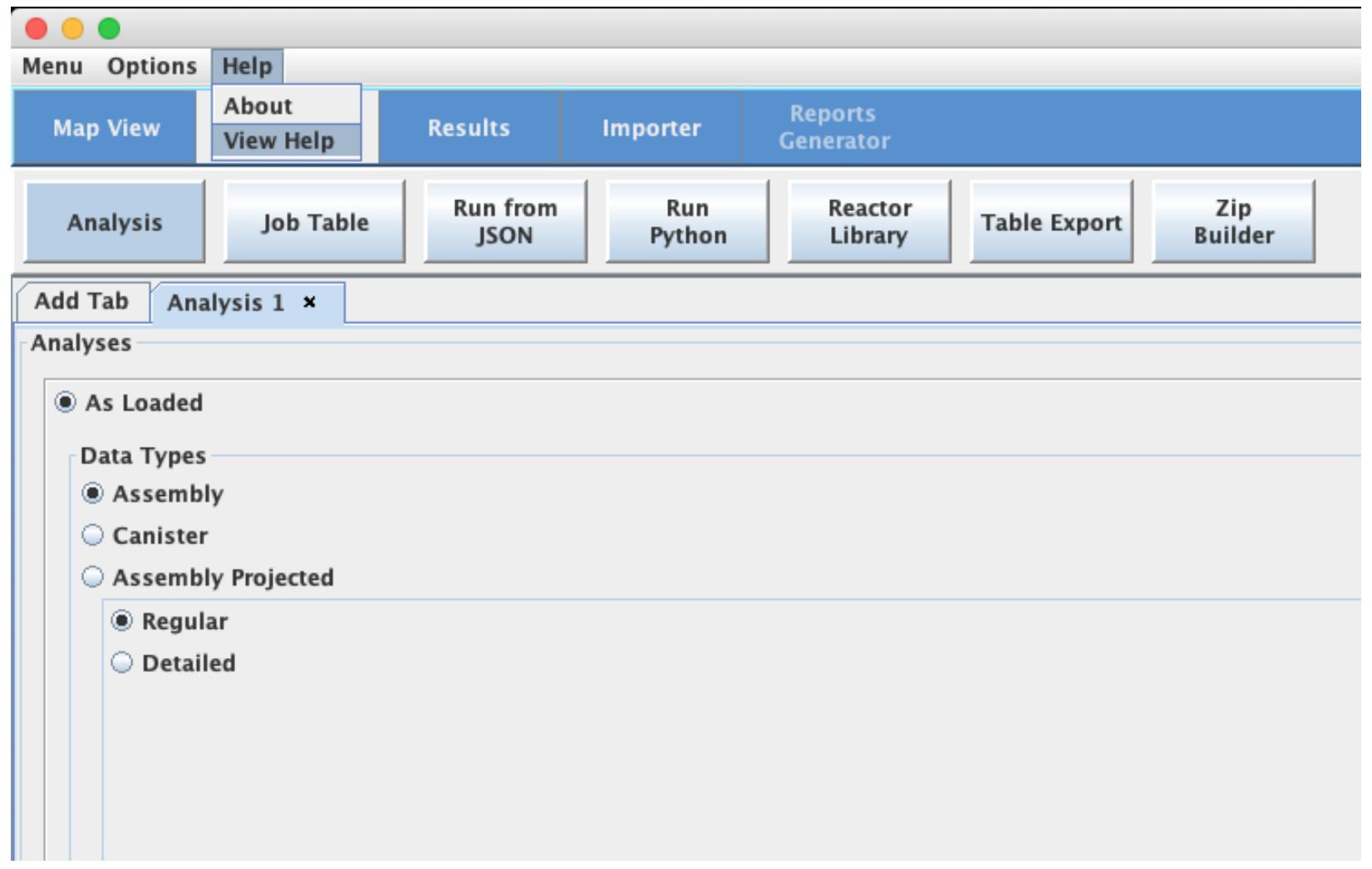

Figure 1. UNF-ST\&DARDS help menu.

\subsubsection{Assembly-specific decay heat calculations}

Assembly-specific decay heat calculation is performed using the Analysis tab of UNF-ST\&DARDS and selecting As Loaded analysis and Assembly data types. The assembly-specific decay heat analysis is described in the UNF-ST\&DARDS manual in the "Assembly-Specific Decay Analysis" subsection under the "Analysis and Result Visualization" section. 


\subsubsection{Assembly-specific dose rate analysis}

Assembly-specific dose rate analysis is not currently included in the UNF-ST\&DARDS manual. This section briefly describes assembly-specific dose rate analysis using a site called "Generic Site." To perform an assembly-specific dose rate analysis, click the As Loaded radio button in the Analysis navigation menu as shown in Figure 2. Select the Assembly button from the Data Types (default) and click the Next/Forward ( $>$ ) button (bottom right). The next step will appear as shown in Figure 3.

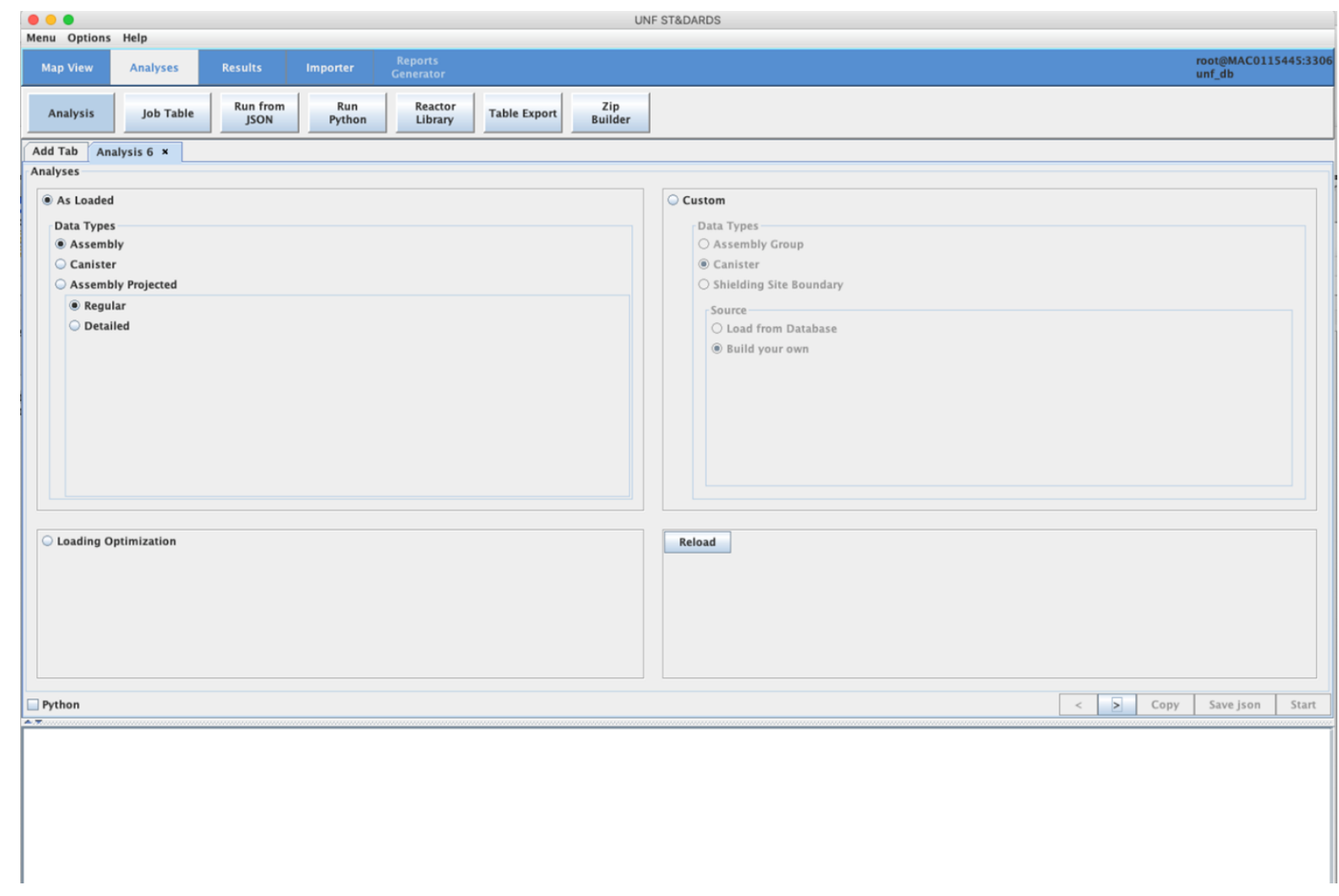

Figure 2. UNF-ST\&DARDS as-loaded analysis. 


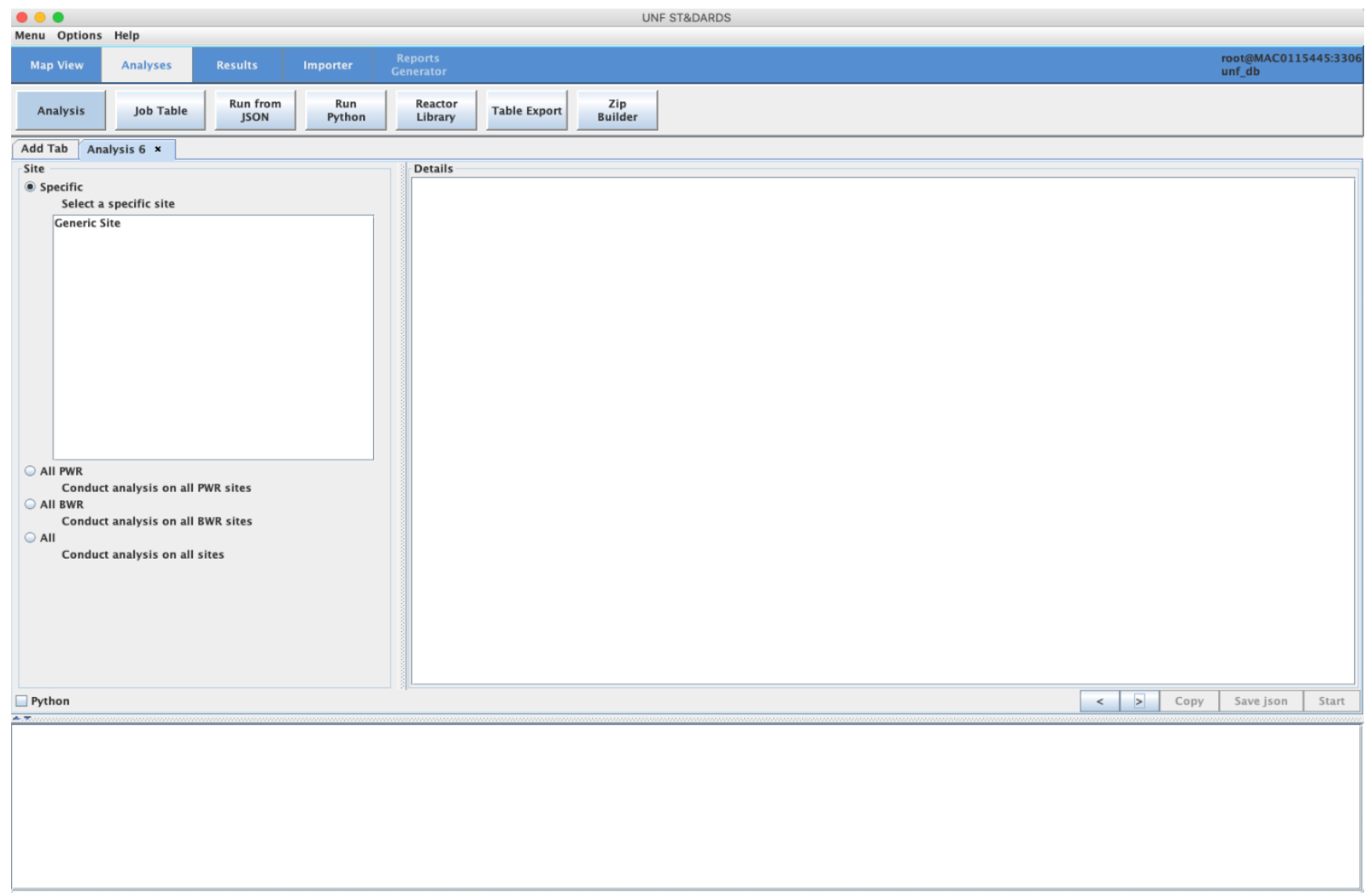

Figure 3. Assembly-specific analysis for generic site.

Selecting Generic Site in the Select a specific site box will display all the assemblies at that site in the Details panel as shown in Figure 4. The user can switch between sites by selecting a specific site from the Select a specific site box (Only Generic Site is visible in the example because data were added only for Generic Site for this exercise). The specific assemblies can be selected for analysis by checking the Run box as shown in Figure 4. Right-clicking on the Details panel will show options for selecting/deselecting all assemblies, as shown in Figure 4. The user is encouraged to closely examine all of the columns to understand the data. The columns are intended to be self-explanatory. Clicking the Next/Forward button will take the user to the next analysis step, as shown in Figure 5. 


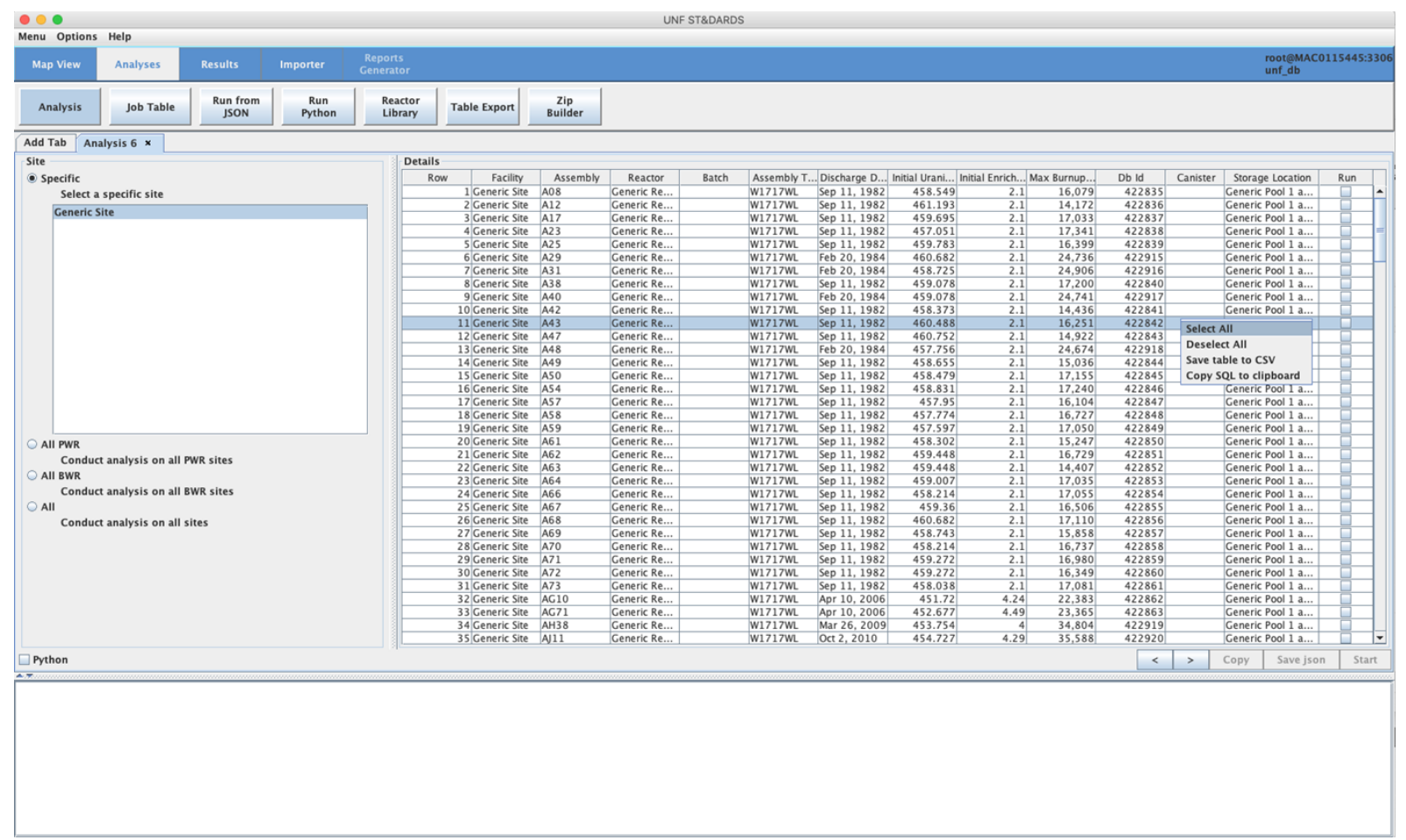

Figure 4. Assemblies at generic site.

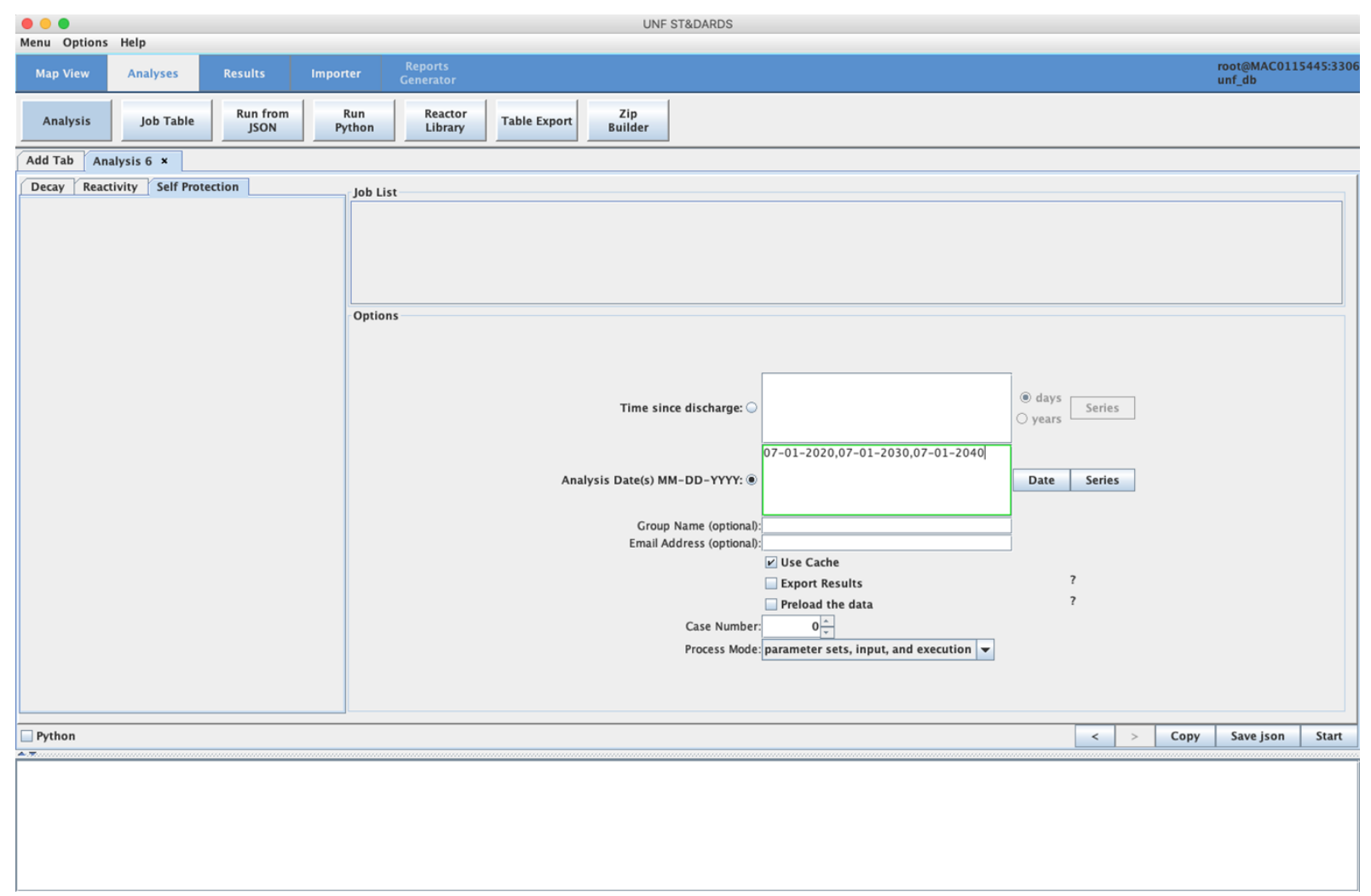

Figure 5. Parameter selection for assembly-specific dose analysis. 
As shown in Figure 5, UNF-ST\&DARDS provides three assembly-specific analysis options: Decay (default selection), Reactivity, and Self Protection. In this step, the user should select the Self Protection tab as shown in Figure 5. The user must provide a cooling time: Time since discharge as shown in Figure 5, or Analysis Date(s). This tutorial uses three Analysis Date(s) as shown in Figure 5 (07-01-2020, 07-01-2030, and 07-01-2040). The user must now select a Process Mode. The Parameter Sets, Input, and Execution option is selected for this analysis. Clicking the Start button will open a tab in Job Table for tracking the analysis. The analysis completion message will appear at the bottom bar in the Job Table (see manual for details).

\subsubsection{Inventory projection}

Dry storage loading optimization uses a projected inventory based on the current inventory for the projected reactor shutdown date. The methodology used by UNF-ST\&DARDS projection tool is documented in the validation report by Vinson [8]. Based on the validation report findings [8], the methodology/option shown here report uses the last five historical cycles of data to project fuel discharges, with no adjustment for the reactor-specific capacity factors or the Energy Information Administration-forecasted nuclear energy demand.

The inventory projection tool in not currently integrated into UNF-ST\&DARDS; however, the tool uses the UNF-ST\&DARDS database to obtain data on the last five historical cycles. The projection tool can be launched by double clicking the InventoryProjection.jar inside the Inventory Projection folder in the root UNF-ST\&DARDS location. Figure 6 shows the inventory projection tool.

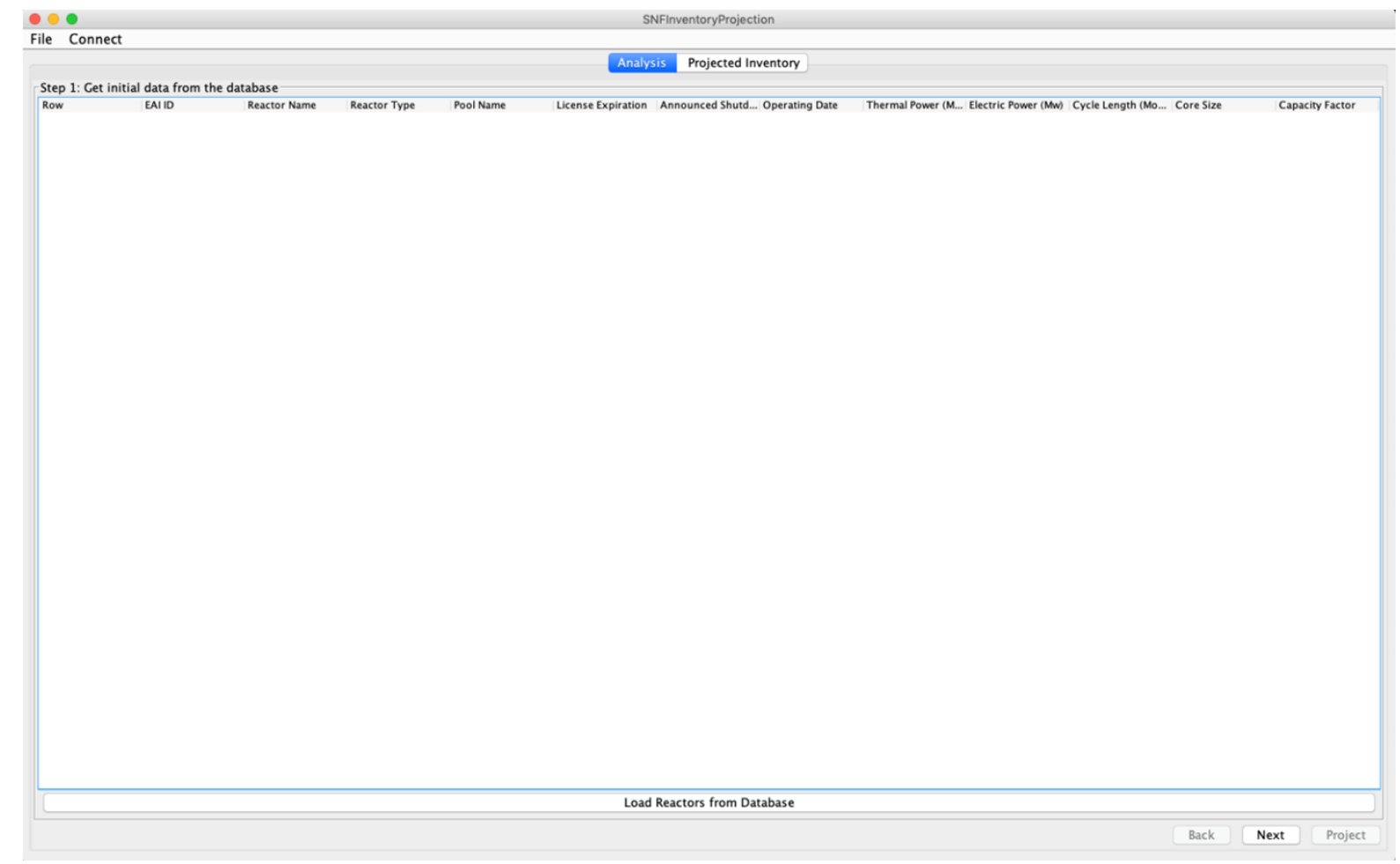

Figure 6. Inventory projection tool.

To use the tool, the user provides one-time UNF-ST\&DARDS database access credentials using the Preferences option from the File menu, as shown in Figure 7 and Figure 8. Database credentials can be found from the unf.rc file located in the UNF-ST\&DARDS root folder. 


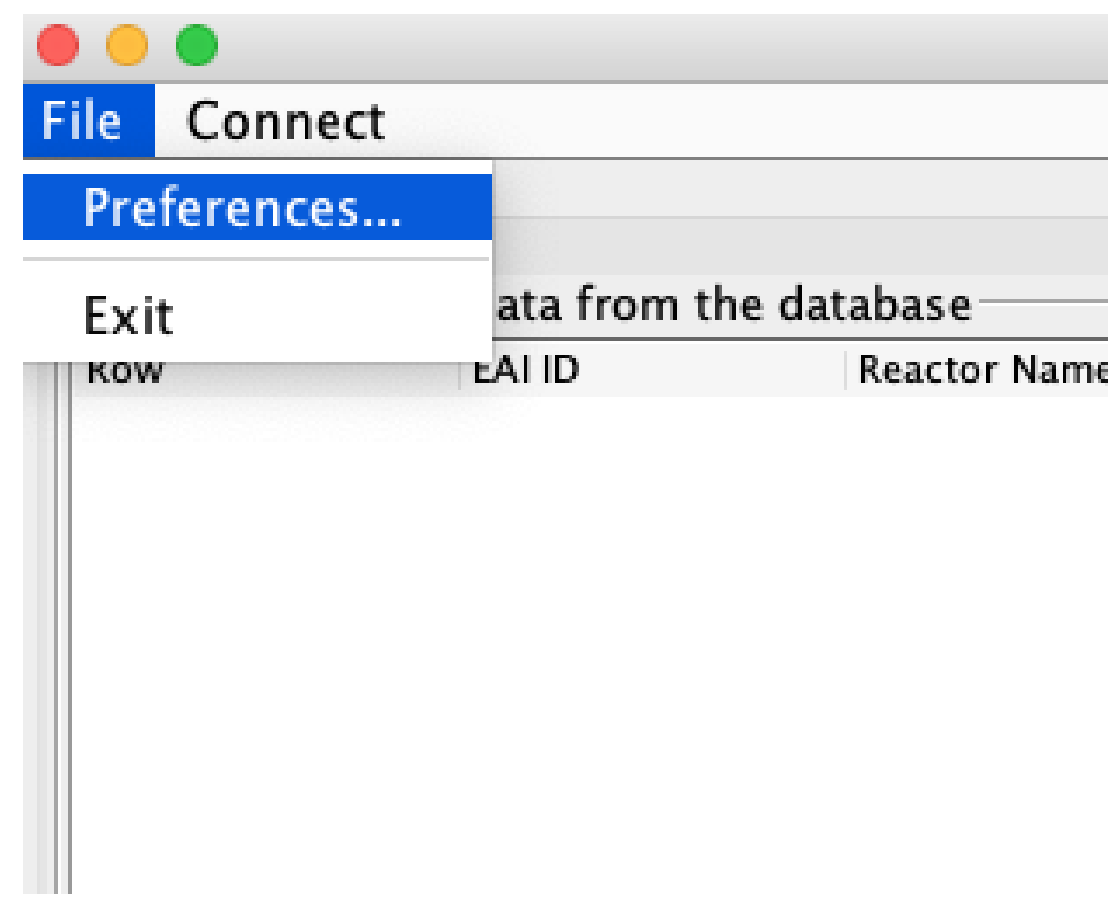

Figure 7. File menu of the inventory projection tool.

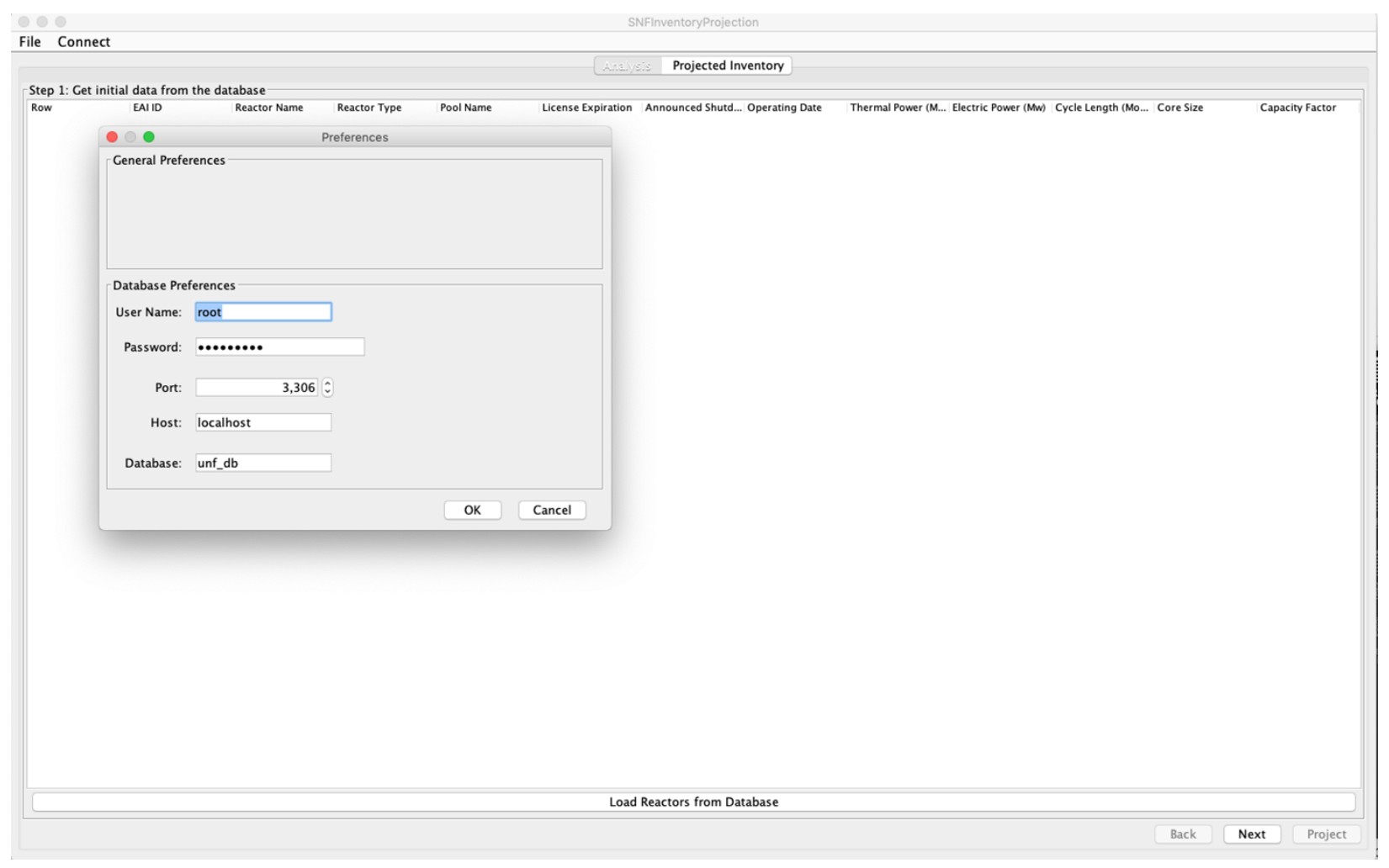

Figure 8. Preference panel of the projection tool showing database credentials.

After providing the UNF-ST\&DARDS database credentials, connection to the database can be established by clicking connect to database from the Connect menu option, as shown in Figure 9. 


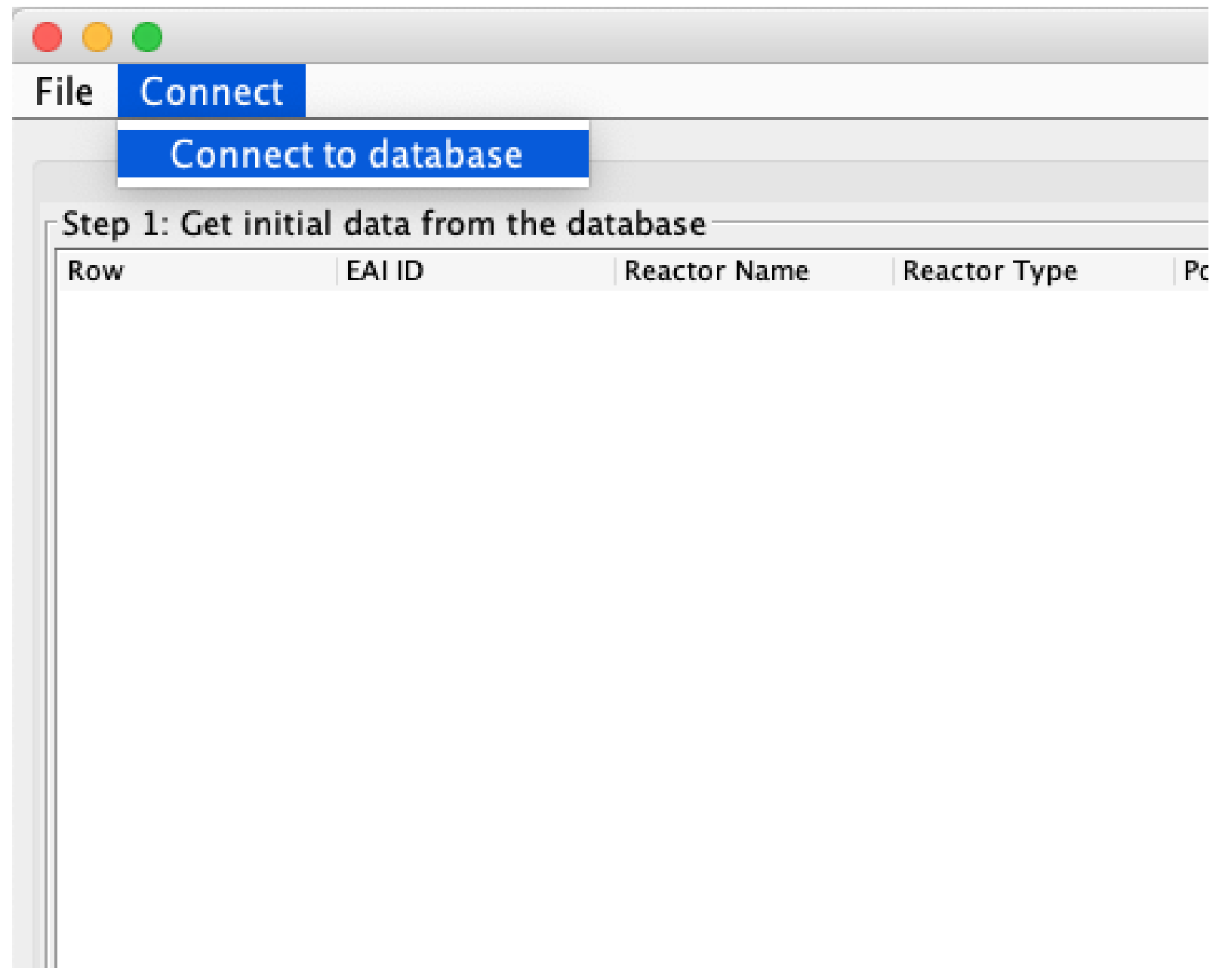

Figure 9. Connect menu option of the inventory projection tool.

Reactor information from the database can be loaded by clicking Load Reactors from Database at the bottom of the panel, as shown in Figure 6. The reactor information will appear in the panel, as shown in Figure 10. The user enters an announced shutdown date if that date differs from license expiration date. In Figure 10,07/01/2050 is entered as the announced shutdown date for Generic Reactor 1 as an example. 


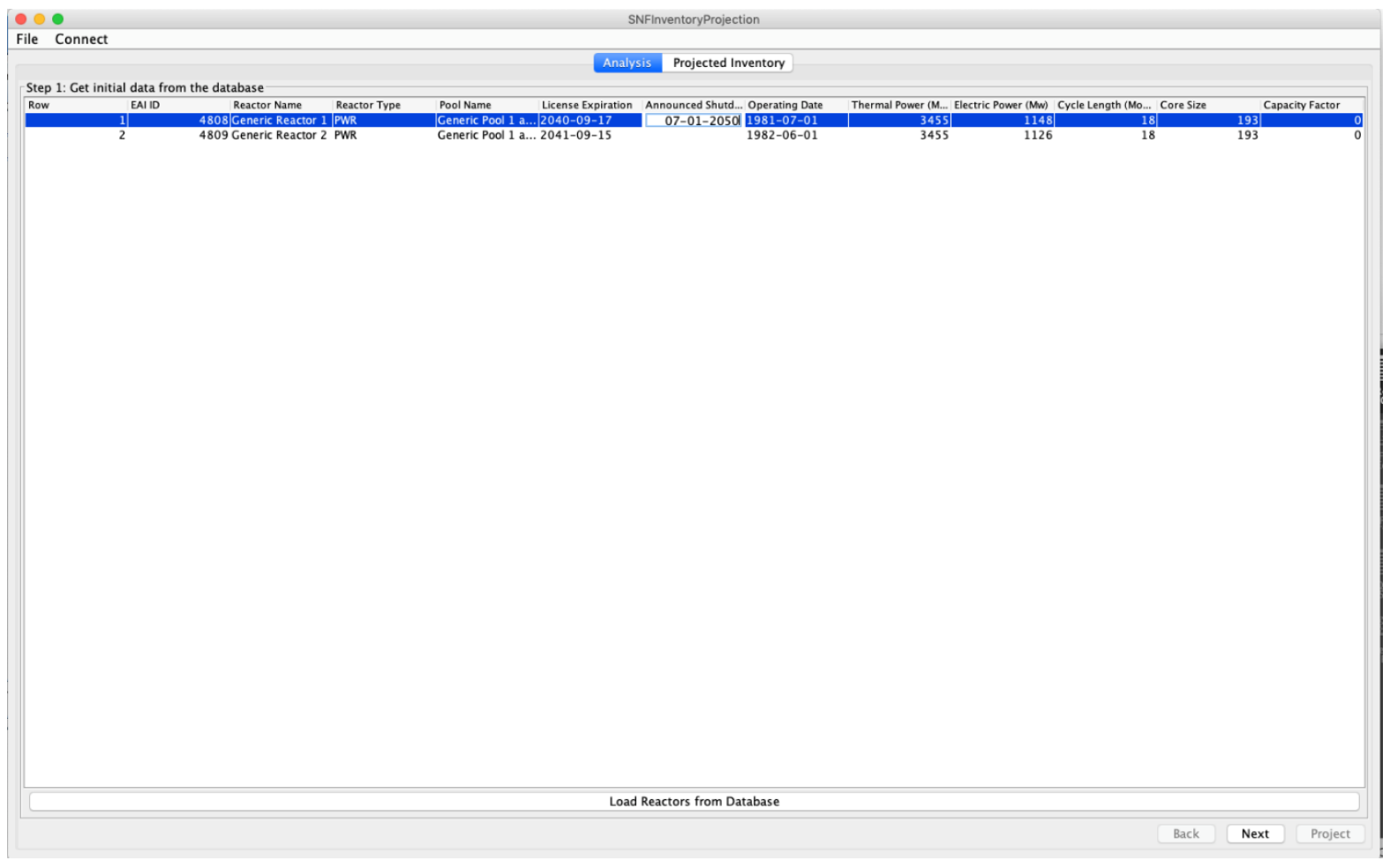

Figure 10. Reactor information displayed in the startup panel of the projection tool.

The Next button at the bottom right corner (Figure 10) will take the user to the case configurations panel, as shown in Figure 11.

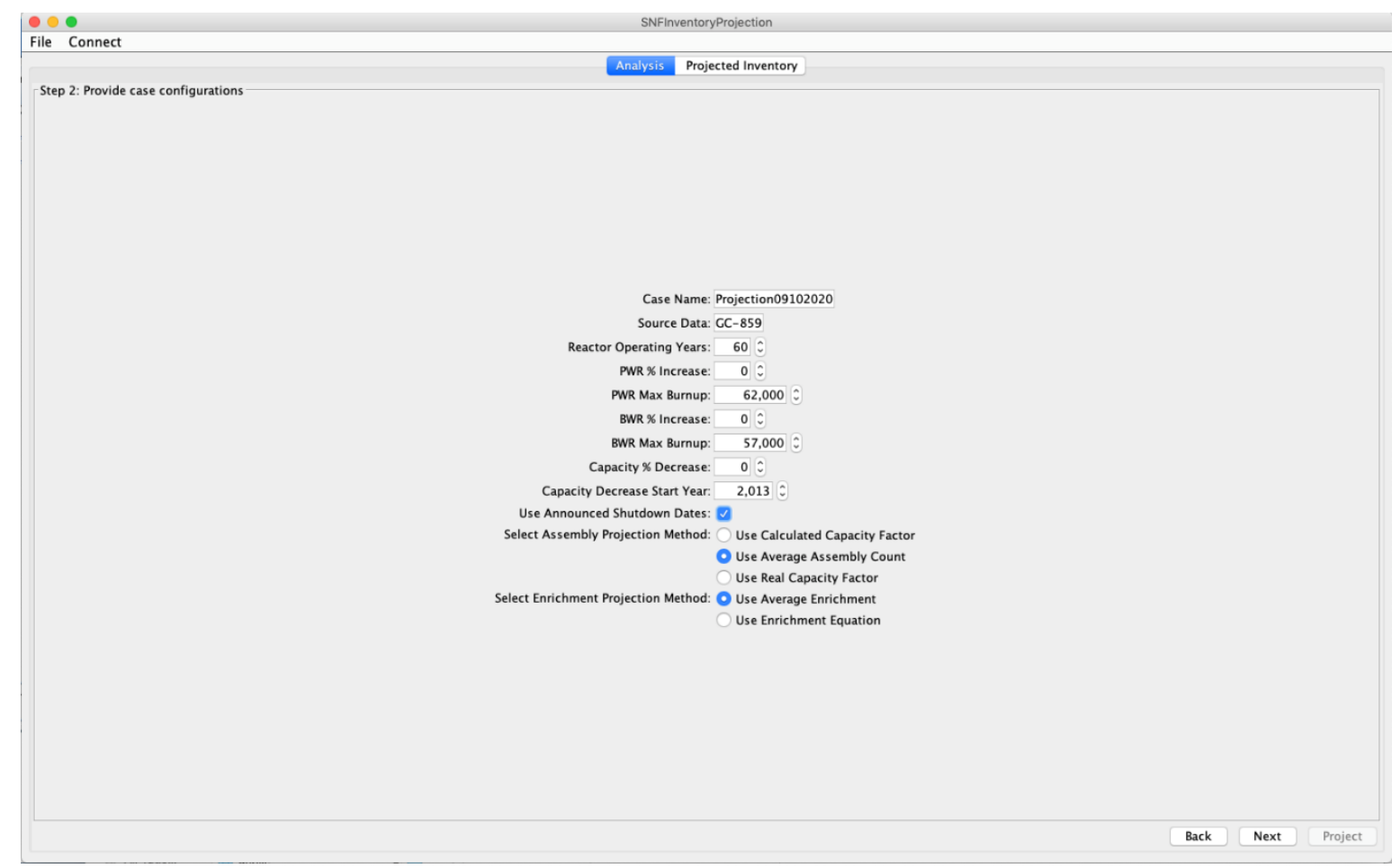

Figure 11. Case configurations panel of the projection tool. 
In the case configurations panel, the user provides a case name (Projection09102020 in Figure 11), source data (GC-859 in Figure 11), reactor operating years (default is 60 as shown in Figure 11), and check the Use Announced Shutdown Dates box if announced shutdown was entered in the previous panel. The current preferred approach [8] is to use the Use Average Assembly Count and Use Average Enrichment, as shown in Figure 11. The user does not need to provide other configurations such as PWR $\%$ increase for this option. The next panel (Figure 12) provides an option for adding future new reactors and models based on an existing reactor from the database. This example does not use a new future reactor for projection.

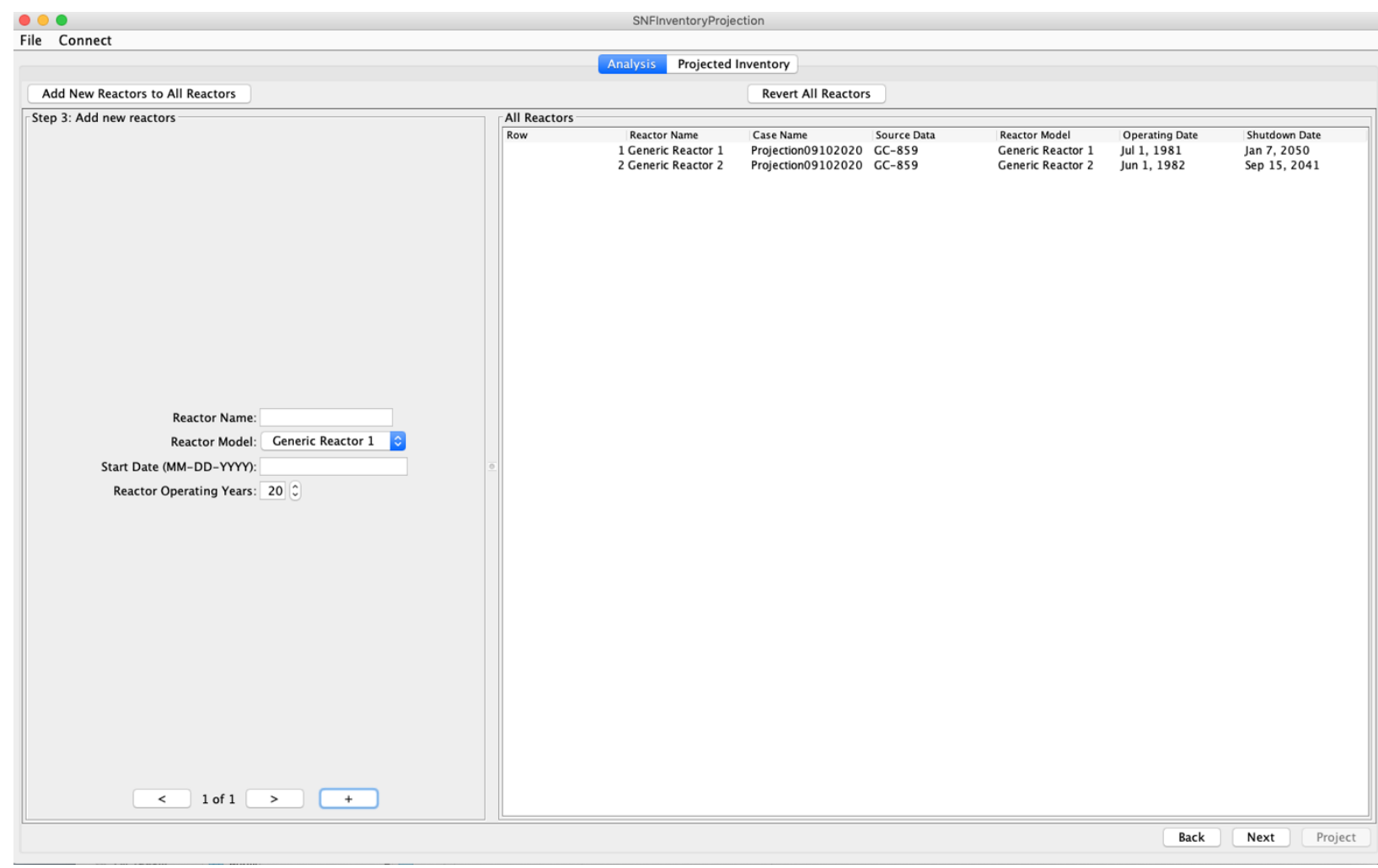

Figure 12. Add new reactors panel in the projection tool.

The next panel displays the projected discharge dates, as shown in Figure 13. 


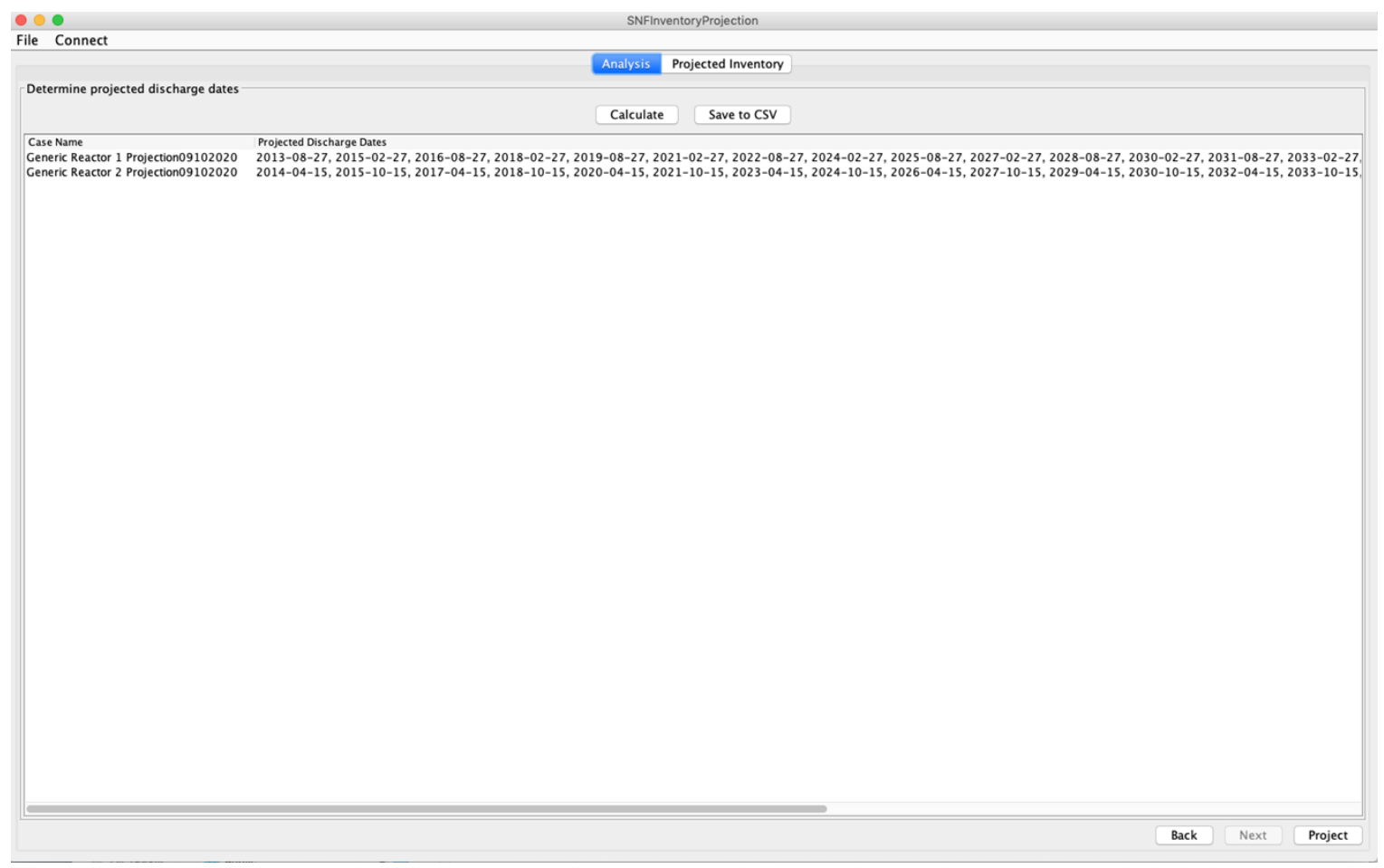

Figure 13. Projected discharge dates for generic reactors 1 and 2.

The project button at the bottom right corner (Figure 13) takes the user to the next panel showing the projected inventory, as depicted in Figure 14. The user clicks the Commit button at the top center (Figure 14) to commit the projected inventory in the UNF-ST\&DARDS database.

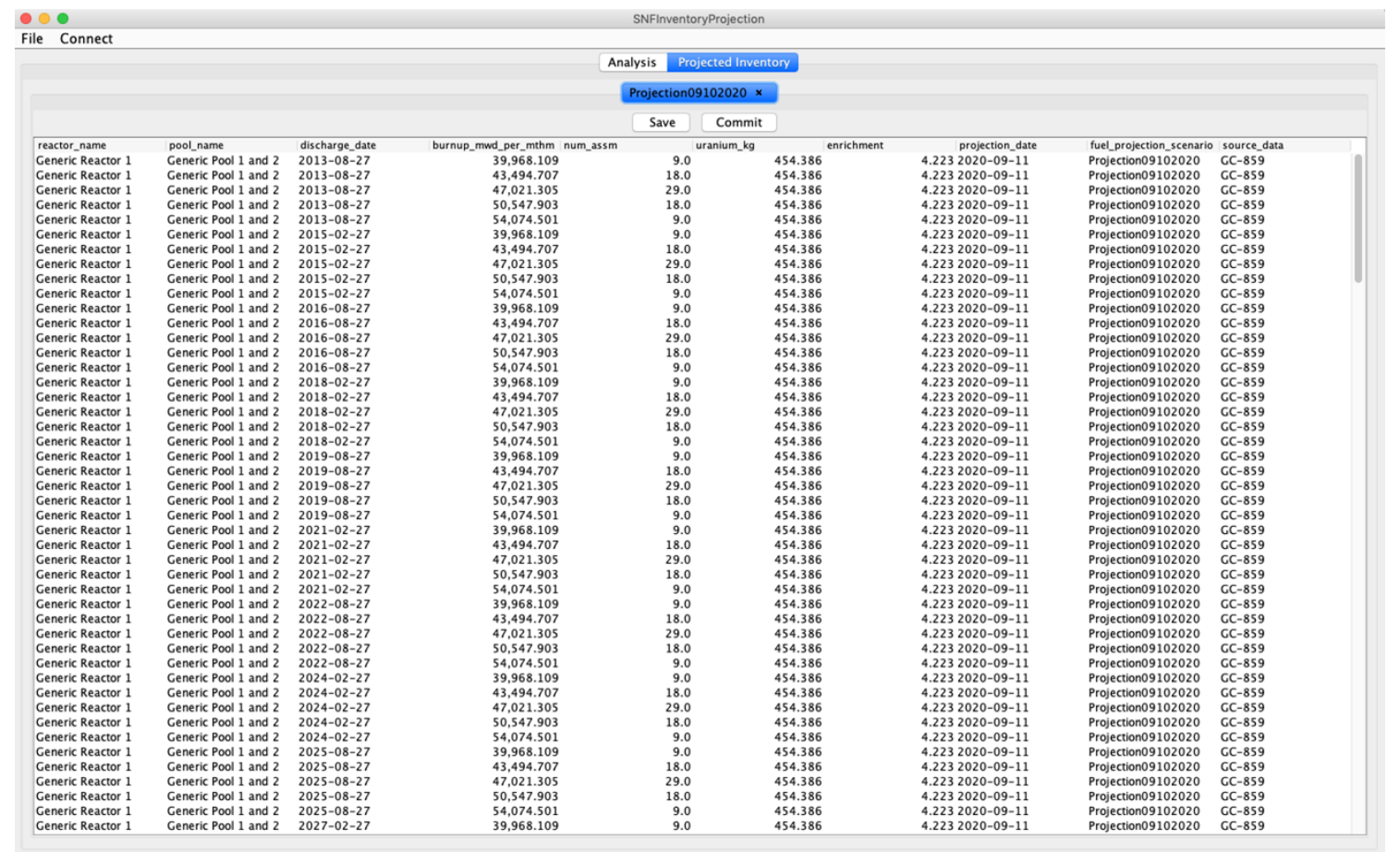

Figure 14. Projected inventory determined by the projection tool. 


\subsubsection{Decay heat analysis of projected inventory}

The user then returns to UNF-ST\&DARDS selects As Loaded in Analysis and then selects Assembly Projected as Data Types to perform the decay heat analysis, as shown in Figure 15. In the next panel, the user selects the projection scenario, enters the analysis dates, and starts the analysis, as shown in Figure 16.

The user is now ready to execute the dry storage loading optimization tool.

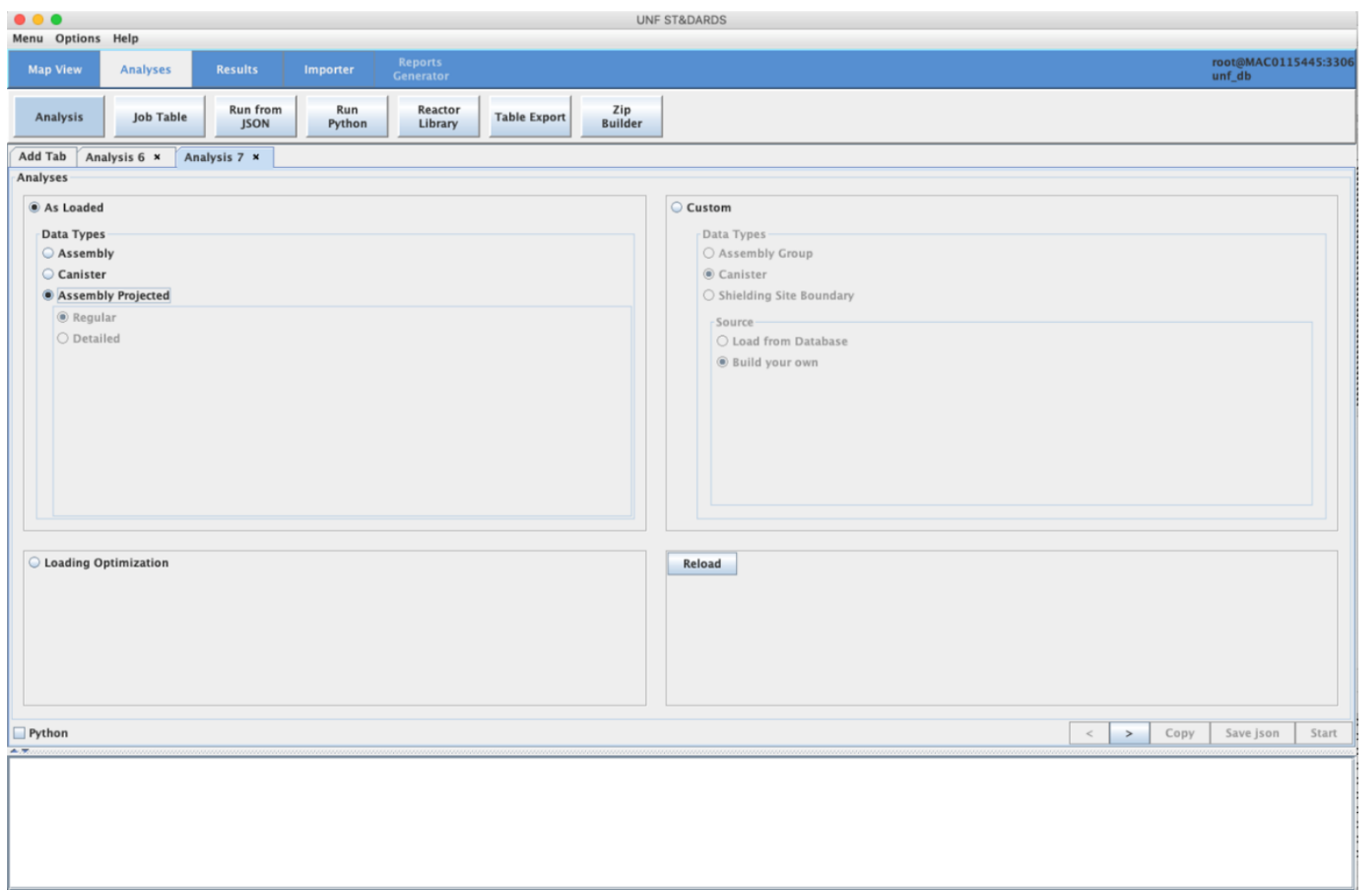

Figure 15. Projected assembly decay heat analysis in UNF-ST\&DARDS. 


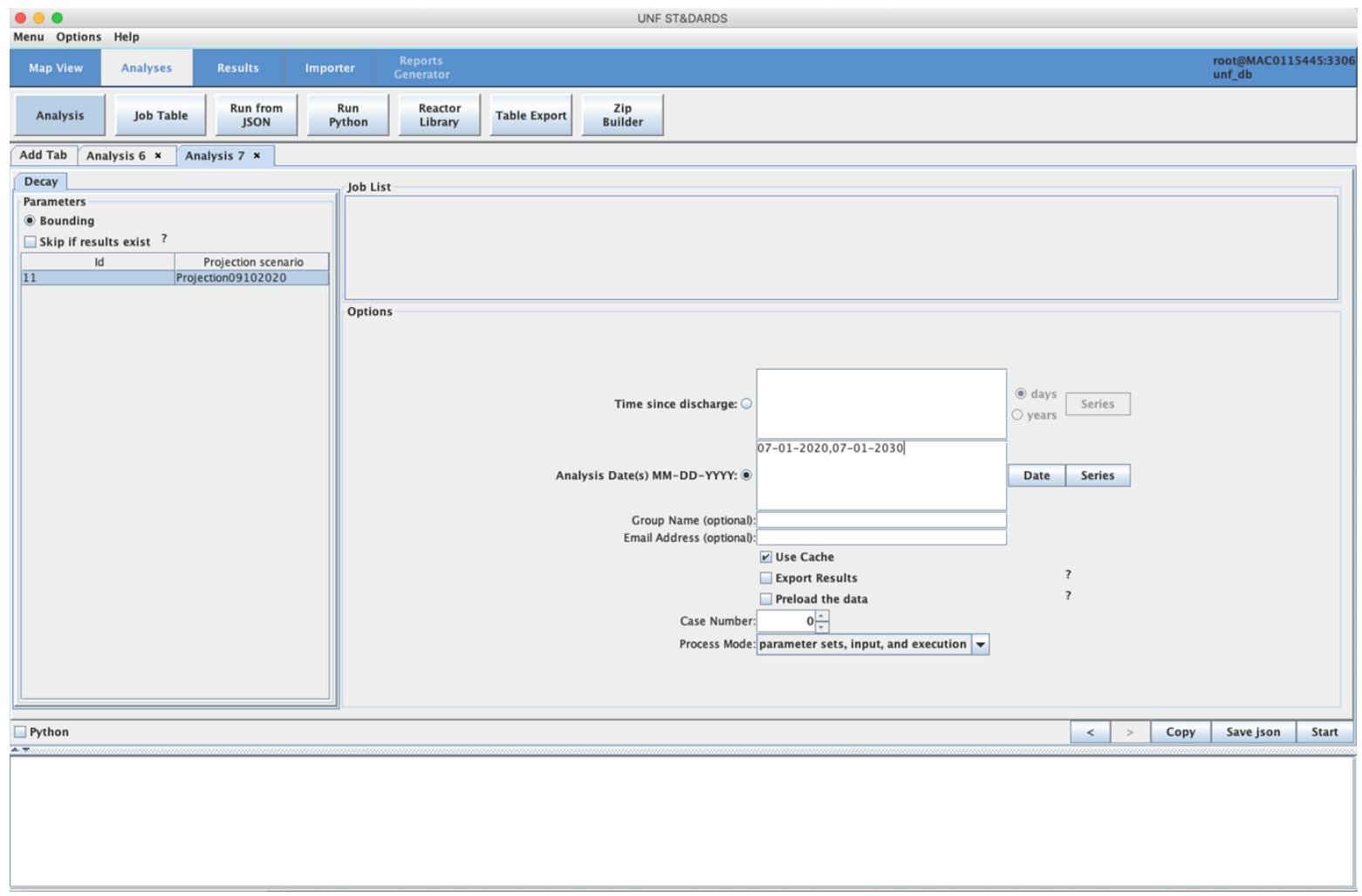

Figure 16. UNF-ST\&DARDS decay heat analysis for projected inventory as a function of analysis dates. 


\subsection{DRY STORAGE LOADING OPTIMIZATION IN UNF-ST\&DARDS}

This section details the effort for integration of the dry storage loading optimization tool, GAMMA-PC [7] into UNF-ST\&DARDS. The details of generating prerequisite data for the analysis in the UNFST\&DARDS are presented in Section 2.1.1.

The UNF assemblies and associated dry storage systems must be comprehensively characterized to support dry storage loading, extended storage beyond the initial 20 years of the storage license, shipping and handling after extended storage, and eventual disposal of the loaded canisters. Most dry casks have been primarily loaded with storage in mind, complicating transportation and long-term storage in the future. With a rapidly growing UNF inventory, a primary area of need in dry storage planning is to apply methodologies to optimize dry cask loading with respect to long-term storage and transportation needs. Integration of the dry storage optimized loading optimization tool into UNF-ST\&DARDS facilitates the formulation of cost-effective solutions, with improved worker safety and efficient transportation timelines. The tool generates optimal loading patterns to balance the competing goals of higher loading capacities, earlier fill and transport times, and overall lower dose rates.

Within this section, a brief description of the optimization algorithm behind the loading optimization tool GAMMA-PC is provided in subsection 2.2.1. The summary of code changes and updates performed to facilitate the integration process is discussed in subsection 2.2.2. The process of performing optimization in UNF-ST\&DARDS in demonstrated in subsection 2.2.3, and select case study results are provided in subsection 2.2.4.

\subsubsection{GAMMA-PC Description}

The dry cask loading problem is a multivariable problem. The solution should not only be able to handle loading of thousands of assemblies into dry casks, but it also should have considerations for licensing and operational constraints related to heat loads, dose rates, and cask loading timelines. Furthermore, the characteristics and the timeline of the future assemblies to be added to the solution method are uncertain.

GAMMA-PC uses a metaheuristic algorithm that combines various aspects of the adaptable dynamic bin packing problem [7]. While the details behind the formulation of the optimization algorithm are described in depth in the literature [7], this section provides a concise summary of the underlying methodology.

\subsubsection{Optimization Methodology}

The dry cask loading problem has three competing goals: (1) minimizing the number of casks needed, (2) reducing the initial heat loads in the cask, and (3) minimizing the storage time required before the casks can be ready for transport. This essentially makes it a 3D minimization problem.

$$
\text { Solution = minimize }[(\# \text { of casks), (initial heat load), (transport time) }]
$$

Since multiobjective problems have competing goals, a single solution cannot fulfill all the objective functions. Such problems are generally solved as a set of solutions called a Pareto set, in which the solutions involve trade-offs between the different objectives. The cask loading problem is categorized as a bin-packing problem in which there are $\mathrm{N}$ number of items to be packed into as few bins as possible within in the problem constraints applied. Traditional bin packing problems often used first fit or best fit methods to generate a single solution. Such methods are useful for smaller problems, but they are computationally expensive and ineffective for larger problems. Approximate dynamic algorithms like the one use for GAMMA-PC produce a set of near optimal solutions within the defined constraints while significantly reducing problem time.

Using the premise of the bin packing problem, GAMMA-PC uses certain decision variables to formulate an objective solution space. The problem in Eq. (1) can now be represented as follows: 


$$
X=\left[x, y, t_{f i l l}\right]
$$

where

$x \quad$ is a matrix of assemblies to be loaded in the cask,

$y \quad$ is an array of casks available to load the assemblies, and

$t_{f i l l}$ is a continuous variable indicating the time each cask is loaded with fuel assemblies.

The variable $y$, which represents the number of casks available to load, is given a theoretical maximum value to avoid loading of near-empty casks. In an ideal situation, all the casks would be filled to the full capacity of number of assemblies; however, to accommodate situations in which there may be a need for empty spaces to meet other loading constraints, the theoretical maximum number of casks is set to allow each cask to be filled at $75 \%$ capacity as long as the number of assemblies are evenly distributed across the cask.

Other loading constraints are added to further define the problem set. Some examples are given below:

- $\quad$ bin packing constraints such as requiring that each assembly can only be assigned to one cask and that casks are not filled beyond their capacity

- $\quad$ the burnup of each assembly meets the maximum burnup specified in the CoCs, and the decay heat limits for the cask type are met

- $\quad$ the pool is assumed to have completed decommissioning at a specified period after the last projected discharge (5 years used in GAMMA-PC), and all assemblies in a single cask are assumed to originate from the same pool to meet the pool close date.

With the constraints defined and the solution set outlined, GAMMA-PC runs a population-based metaheuristic algorithm in which a greedy randomized adaptive search procedure (GRASP) governs the packing and local search, and various packing methods and other heuristics are applied. At the end of the computation, a set of solutions that meets all the specified loading constraints and fulfills optimization objectives is generated.

To compare the solution set from GAMMA-PC against the traditional first fit methods, a set of solutions based on the oldest, coldest method are also developed. The oldest, coldest strategy is a simple first fit approach based on loading of the oldest and coldest fuel assemblies that were first placed in the cask.

\subsubsection{Data Input from UNF-ST\&DARDS}

To generate the optimized loading maps, GAMMA-PC requires detailed information about the current and projected assemblies, the casks into which these assemblies will be loaded, the site and pool information, and other relevant loading constraints. GAMMA-PC uses UNF-ST\&DARDS to obtain all the necessary information needed. The process for preparation of required data for optimization is described in detail in Section 2.1.1.

The underlying algorithm for GAMMA-PC is written in the Python programming language, which allows it to have a modular structure. Different modules within the code provide the assembly, cask, and the site information from UNF-ST\&DARDS to the optimization module. This data are drawn from UNFST\&DARDS using a set of queries developed in structured query language (SQL). The Unified Database in UNF-ST\&DARDS integrates an open source, relational MySQL Community edition database [9]. The data in MySQL are stored as a collection of structured information in separate tables that are linked to each other. This allows for structured collection and manipulation of the data without imposing a large computational burden. 
The information from the database, which has been selected for the site being optimized, is then provided to the algorithm through the modules within GAMMA-PC for further processing. An infographic layout of the process is shown in Figure 17 [7].

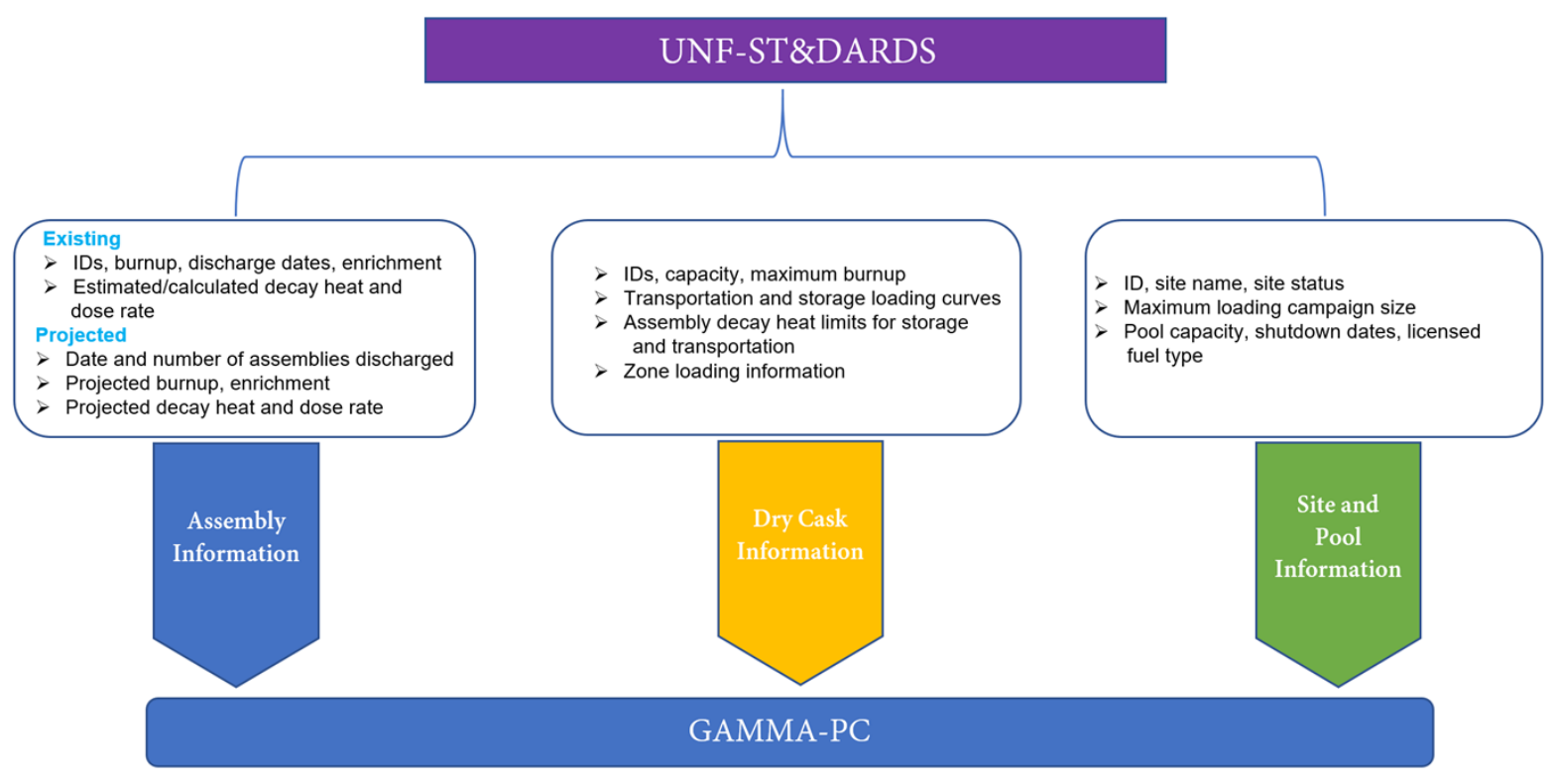

Figure 17. UNF-ST\&DARDS data input to GAMMA-PC.

\subsubsection{UNF-ST\&DARDS Integration of Optimization Tool}

To further enhance the capabilities of UNF-ST\&DARDS as a single point solution for the UNF-related analyses, the GAMMA-PC code was integrated into UNF-ST\&DARDS. This section details the changes and updates performed to facilitate the integration.

\subsubsection{GAMMA-PC Code Updates}

A series of changes were made to the GAMMAP-PC code structure and modules to facilitate a seamless integration into UNF-ST\&DARDS. While the primary codebase itself was only sparsely modified, changes to the code input structure were made to allow the optimization to be run from the graphical user interface (GUI) within UNF-ST\&DARDS. The changes made to the GAMMA-PC code are detailed below:

\section{New modules added}

- Optimize.py: This module is an input processor that works as a bridge between user input data in the UNF-ST\&DARDS GUI and the optimization code. The module takes site and cask loading related inputs provided by the user and passes them on to the appropriate GAMMA-PC modules. Post optimization, it also calls upon the modules that post-process the data to generate csv files and visual plots of the loading information.

- Process_data.py: This module processes outputs from the optimization runs and delivers them out into user friendly formats (csv files and visual plots). As described previously, GAMMA-PC generates a set of optimal solutions that meet all the defined constraints for the problem. The get_sol () function within this module reads all the solution sets and selects the solution that requires the lowest number of casks. If multiple solutions have the same lowest number of casks loaded, then it uses the average initial heat load as the secondary parameter for the solution selection. 
For the example shown in Figure 18, the function will select solution 7403 based on the number of casks loaded.

\begin{tabular}{rrrr}
\multicolumn{5}{c}{ No. of Casks } & Avg. Initial Heat Load (kW) & Max. Year to Transport \\
Solution ID & & & \\
\hline 7403 & 227 & 16.587184 & 2078 \\
7402 & 228 & 16.511723 & 2078 \\
7399 & 229 & 16.434229 & 2078 \\
6957 & 230 & 16.346306 & 2078 \\
6958 & 231 & 16.296484 & 2078 \\
$\mathbf{5 4 8 0}$ & 232 & 16.276064 & 2078 \\
$\mathbf{6 9 6 4}$ & 233 & 16.176146 & 2078 \\
6965 & 234 & 16.125342 & 2078 \\
$\mathbf{6 9 6 1}$ & 237 & 16.071914 & 2078 \\
7187 & 238 & 15.997243 & 2078 \\
6547 & 239 & 15.992543 & 2078 \\
6749 & 240 & 15.893181 & 2078
\end{tabular}

Figure 18. Sample solution sets generated by GAMMA-PC.

- Once the solution set is identified, the get_data () function generates the loading optimization information and prints it out to a csv file. The first part of the printed csv file generates information regarding each of the casks loaded, as shown in Figure 19.

\begin{tabular}{rrrrrr} 
& Cask ID & Fill Ready Date & Trans. Ready Date & Total Decay Heat & Loading Date \\
\hline $\mathbf{0}$ & $\mathbf{1}$ & $2013-10-31$ & $2031-07-01$ & 15.701714 & $2024-05-20$ \\
$\mathbf{1}$ & 2 & $2018-02-04$ & $2033-04-21$ & 16.335340 & $2024-05-20$ \\
$\mathbf{2}$ & 3 & $2018-03-21$ & $2029-11-08$ & 18.859102 & $2024-05-20$ \\
$\mathbf{3}$ & 4 & $2018-03-28$ & $2027-07-22$ & 17.261908 & $2024-05-20$ \\
$\mathbf{4}$ & 5 & $2018-05-07$ & $2031-12-28$ & 14.778444 & $2024-05-20$ \\
$\mathbf{5}$ & 6 & $2018-05-09$ & $2027-11-19$ & 19.319146 & $2024-05-20$ \\
$\mathbf{6}$ & 7 & $2018-08-10$ & $2031-10-29$ & 19.834629 & $2024-05-20$ \\
$\mathbf{7}$ & 8 & $2019-04-12$ & $2033-12-17$ & 20.623509 & $2024-05-20$ \\
$\mathbf{8}$ & 9 & $2019-04-23$ & $2031-05-02$ & 17.495925 & $2024-05-20$ \\
$\mathbf{9}$ & 10 & $2020-07-09$ & $2025-10-30$ & 15.794758 & $2024-05-20$
\end{tabular}

Figure 19. Cask information output from the optimization run. 
Similarly, for each of the casks, detailed information about the assemblies contained within is also generated, as shown in Figure 20.

\begin{tabular}{lrrrrrrrr} 
& Location & Database_ID & Assembly ID & Dis. Date & Burn Up & Decay Heat & Heat Zone & Zone Limit \\
\hline $\mathbf{0}$ & 1 & 337171 & R40 & $2010-04-04$ & 42.608613 & 0.802747 & 1 & 1.42 \\
$\mathbf{1}$ & 2 & 356691 & MM05 & $2009-10-08$ & 51.178000 & 0.990028 & 1 & 1.42 \\
$\mathbf{2}$ & 3 & 347117 & MM10 & $2009-10-08$ & 51.056000 & 0.986909 & 1 & 1.42 \\
$\mathbf{3}$ & 4 & 343876 & N87 & $2007-02-25$ & 38.249000 & 0.567262 & 1 & 1.42 \\
$\mathbf{4}$ & 5 & 355310 & JJ53 & $2005-03-27$ & 39.805000 & 0.539853 & 1 & 1.42 \\
$\mathbf{5}$ & 6 & 403050 & K77 & $2002-09-28$ & 45.726000 & 0.599715 & 1 & 1.42 \\
$\mathbf{6}$ & 7 & 308677 & AA26 & $1994-10-07$ & 14.089000 & 0.150864 & 2 & 0.71 \\
$\mathbf{7}$ & 8 & 308314 & C03 & $1993-10-06$ & 30.165000 & 0.359477 & 2 & 0.71 \\
$\mathbf{8}$ & 9 & 395715 & J41 & $2002-09-28$ & 44.955000 & 0.583018 & 1 & 1.42 \\
$\mathbf{9}$ & 10 & 394851 & K67 & $2002-09-28$ & 46.777000 & 0.617490 & 1 & 1.42
\end{tabular}

Figure 20. Assembly information for the individual casks.

This module also generates a simplified csv file as a data dump for use by the plotting module Caskplot.py. All the data generated by this module are developed for the oldest, coldest solution set for comparison purposes.

- Caskplot.py: This module reads the data dump file created by Process_data.py and generates visual loading maps for each canister. The loading plots generated here are essentially a visual representation of the data presented in Figure 20. Currently, the visual maps are only supported for MPC-68, MPC-32, MPC-37, and MPC-24 cask types. More cask types will be added to the plotting feature in the near future. Examples of generated MPC-68 and MPC-32 cask type plots are shown in Figure 21 and Figure 22, respectively. 


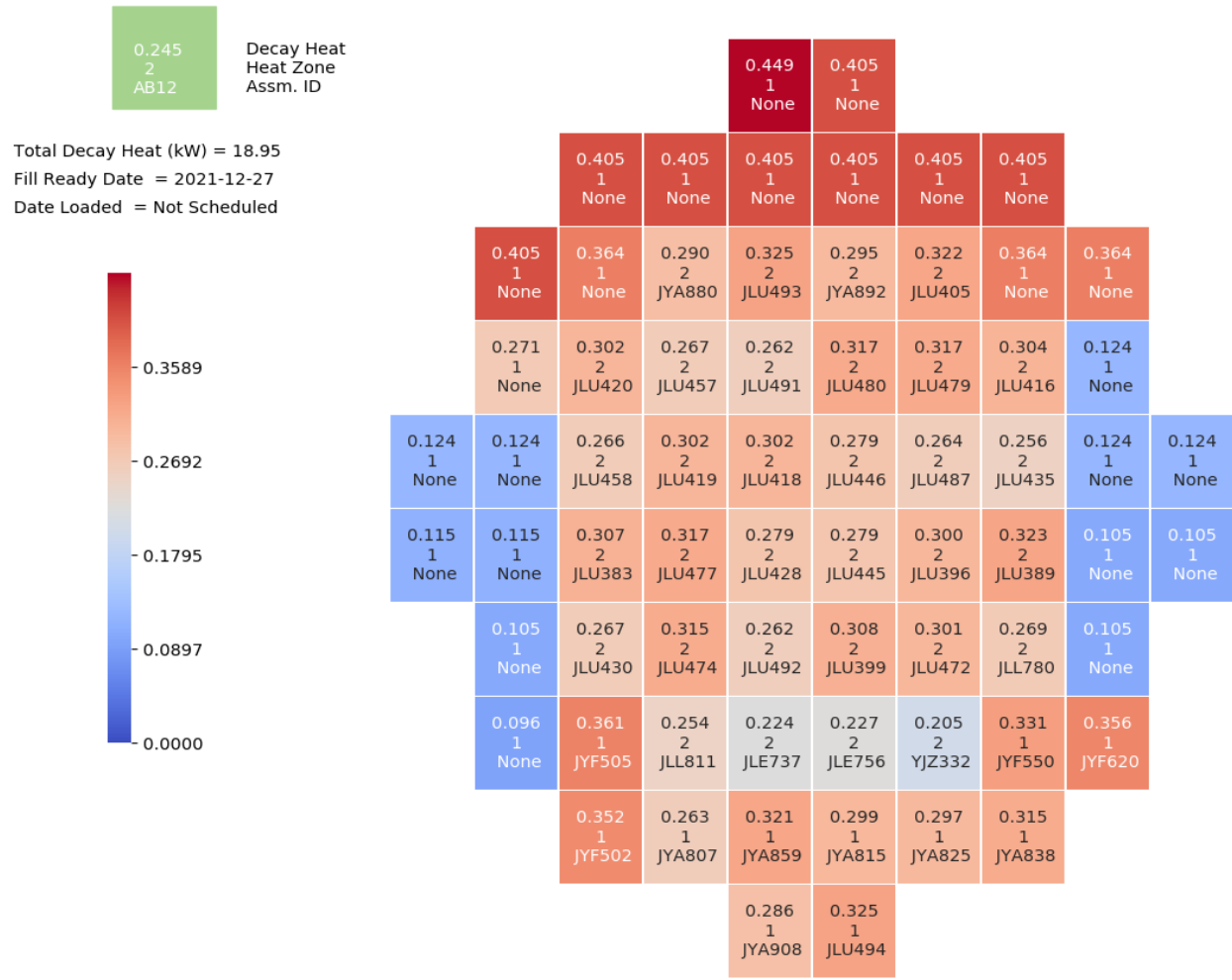

Figure 21. Example loading map for MPC-68 cask.

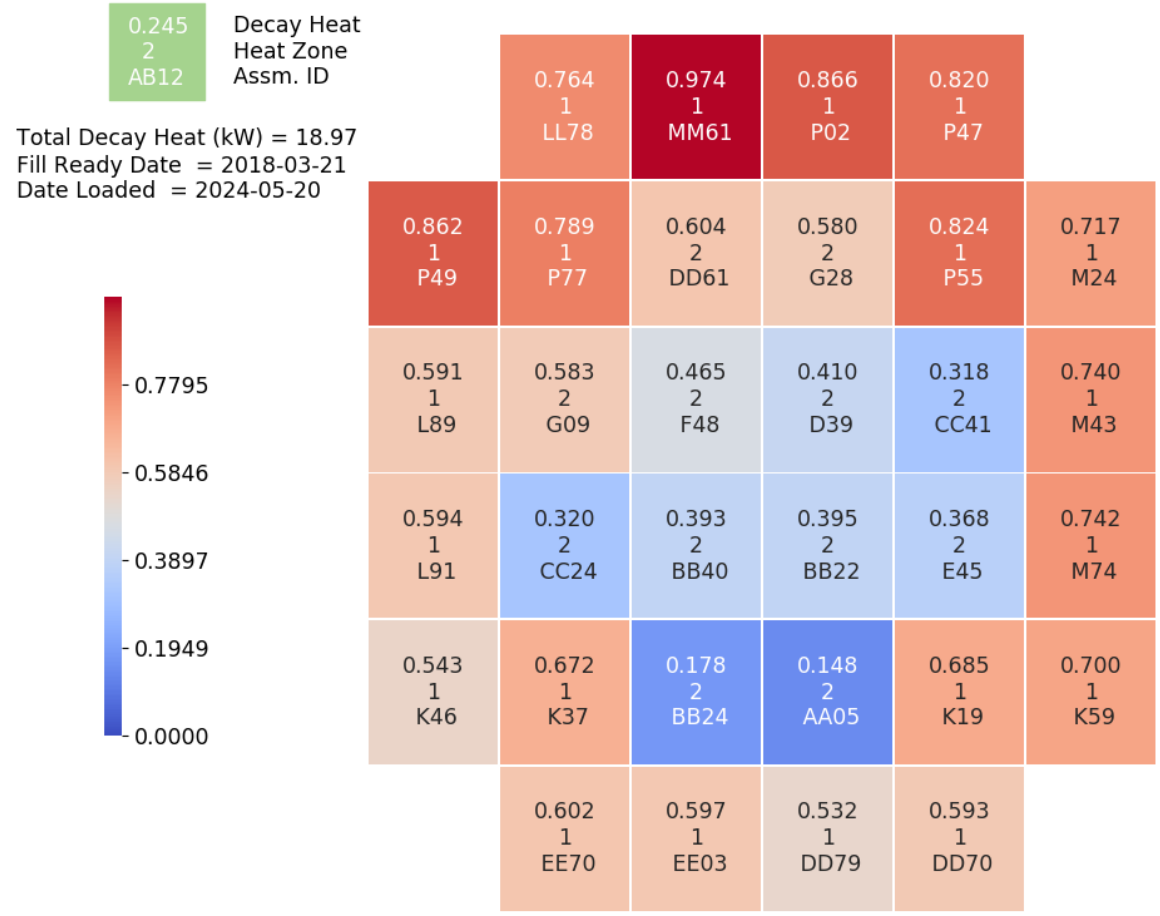

Figure 22. Example loading map for MPC-32 cask. 


\section{Loading schedule}

The Optimize.py module takes in the user supplied loading schedule, in terms of number of canisters and the loading date, and creates a custom loading plan. The GAMMA-PC optimization modules generate the cask loading plans, with the start date based on the latest assembly discharge date and the end date based on the end of the decommissioning period. During this time, it fills the canisters based on a defined, per year maximum fill capacity. Each filled canister is given a Fill Ready Date specifying when it will meet all the storage limits and a Transport Ready Date specifying when it will meet all transportation limits. However, the user is expected to have a loading schedule with different numbers of canisters to be loaded for each campaign.

The Process_data.py module takes in a user-supplied schedule for the loading date and the number of canisters. It then compares the user input Loading Dates with the Fill Ready Dates and loads the number of canisters for that loading period if the first (loading dates) is later than the second (fill ready dates). If more canisters are available to load than the number requested to be loaded, then they are moved forward in the queue for next loading date. The canisters beyond the user input loading dates are shown as Not Scheduled in the loading maps.

An example of the loading schedule is shown in Figure 23. In the example, the user has input the loading schedule for up until 2029. Since only 27 canisters were input for loading, as given by the cask IDs with loading dates provided in the Figure, the remaining canisters show up in the loading map as Not Scheduled.

\begin{tabular}{lrrrrr} 
& Cask ID & Fill Ready Date & Trans. Ready Date & Total Decay Heat & Loading Date \\
\hline 22 & 23 & $2024-04-13$ & $2026-04-28$ & 16.005783 & $2029-05-20$ \\
23 & 24 & $2025-03-25$ & $2030-09-04$ & 15.412273 & $2029-05-20$ \\
24 & 25 & $2025-06-20$ & $2031-05-02$ & 16.450232 & $2029-05-20$ \\
25 & 26 & $2025-06-22$ & $2030-03-08$ & 16.705073 & $2029-05-20$ \\
26 & 27 & $2025-07-04$ & $2028-10-07$ & 14.235319 & $2029-05-20$ \\
27 & 28 & $2025-08-26$ & $2029-04-03$ & 15.566658 & Not Scheduled \\
28 & 29 & $2026-02-27$ & $2028-10-07$ & 13.790654 & Not Scheduled \\
29 & 30 & $2026-04-05$ & $2030-11-03$ & 15.241871 & Not Scheduled \\
30 & 31 & $2026-08-03$ & $2034-06-15$ & 17.056235 & Not Scheduled \\
31 & 32 & $2027-01-03$ & $2030-05-07$ & 15.340170 & Not Scheduled \\
32 & 33 & $2027-02-01$ & $2031-02-01$ & 14.526457 & Not Scheduled \\
33 & 34 & $2027-04-14$ & $2029-08-10$ & 16.374512 & Not Scheduled
\end{tabular}

Figure 23. User input loading schedule.

\section{Changes to the existing modules}

A few minor changes were implemented to the existing GAMMA-PC code. The changes applied are as follows:

- caskbuilder . py: With the UNF-ST\&DARDS integration, the user will have an option to add or update the cask-related information, including the loading curve, storage heat maps, transport heat maps, burn up information, and loading zones. This information is currently extracted in the code 
from the UNF-ST\&DARDS using the makecaskobject ( ) function in the module. The userselected information from the GUI will now be directly provided to the DryCask class within the caskbuilder.py module through the Optimize.py input processor.

- targetdose.py: Since the user will provide most of the cask-related information through the UNF-ST\&DARDS GUI, the interpolation calculations for the per-assembly dose will now be performed by this module. This module basically uses the same code for the calculation that was previously part of the caskbuilder. py module.

- facility.py: The maximum fill cap for each year was updated from 10 to 12 . This value sets the upper limit for how many casks are allocated on the same Fill Ready Date. The value was increased because in some shorter optimization schedules, the fill cap was exceeded during testing. As the actual loading cycle is determined by the loading schedule input from the user, this value does not impact the overall loading.

\subsubsection{Performing Loading Optimization in UNF-ST\&DARDS}

The details of generating the prerequisite data for performing loading optimization in UNF-ST\&DARDS are provided in depth in Section 2.1.1. This section discusses performing the loading optimization using UNF-ST\&DARDS.

Once all the data are generated, the user selects Loading Optimization from the GUI and clicks the Next/Forward $(>)$ button, as shown in Figure 23.

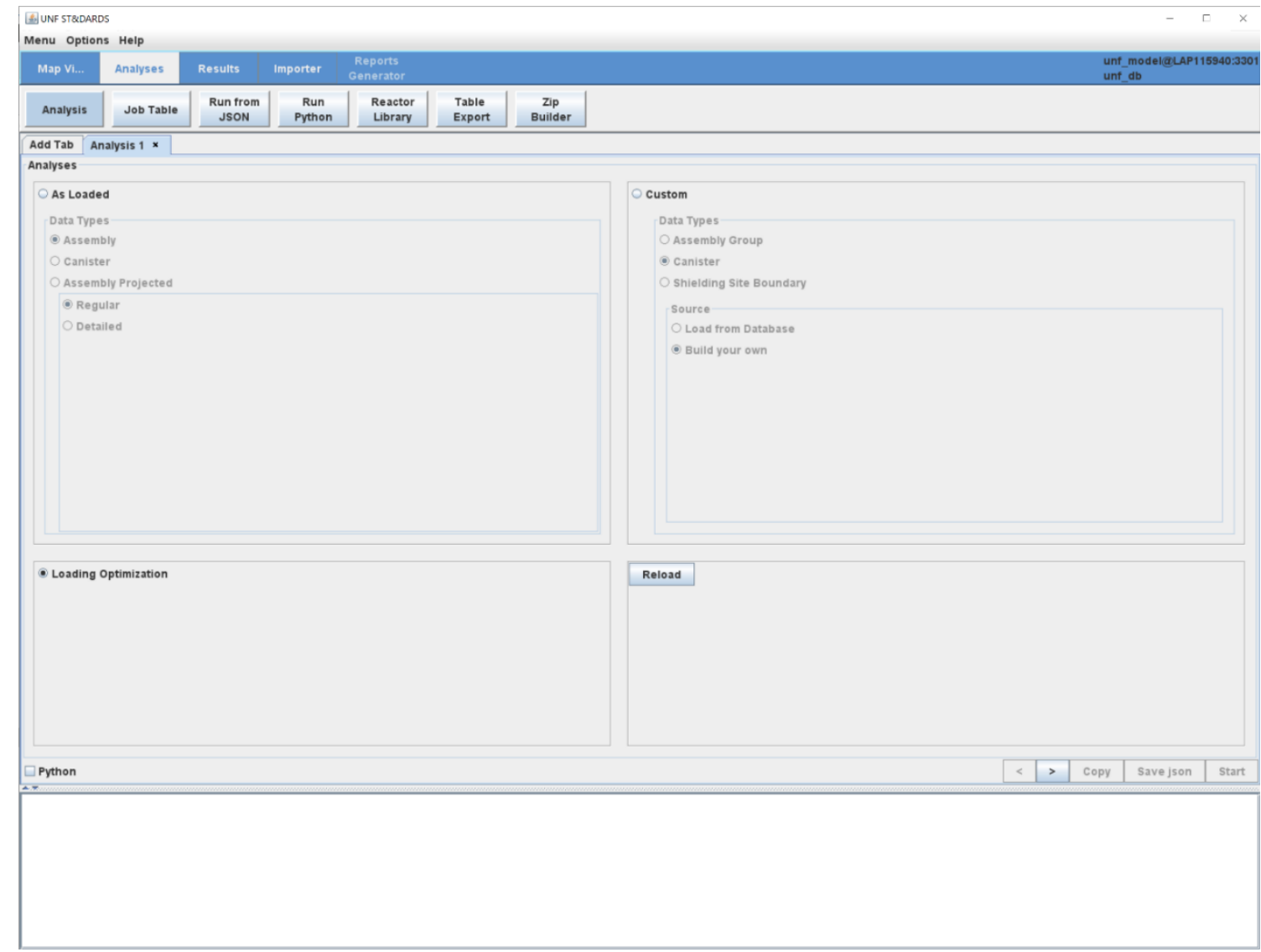

Figure 24. Starting loading optimization in UNF-ST\&DARDS. 
This takes the user to the next step, where the user selects the site to optimize with the associated canister model, as shown in Figure 25. It is worth reiterating here that since the UNF-ST\&DARDS released version does not contain reactor-specific inventory, assembly-specific decay heat, projected inventory, or decay heat of projected inventory, the user will be only able to perform optimization for the site for which the data have been prepared, as described in Section 2.1.1.

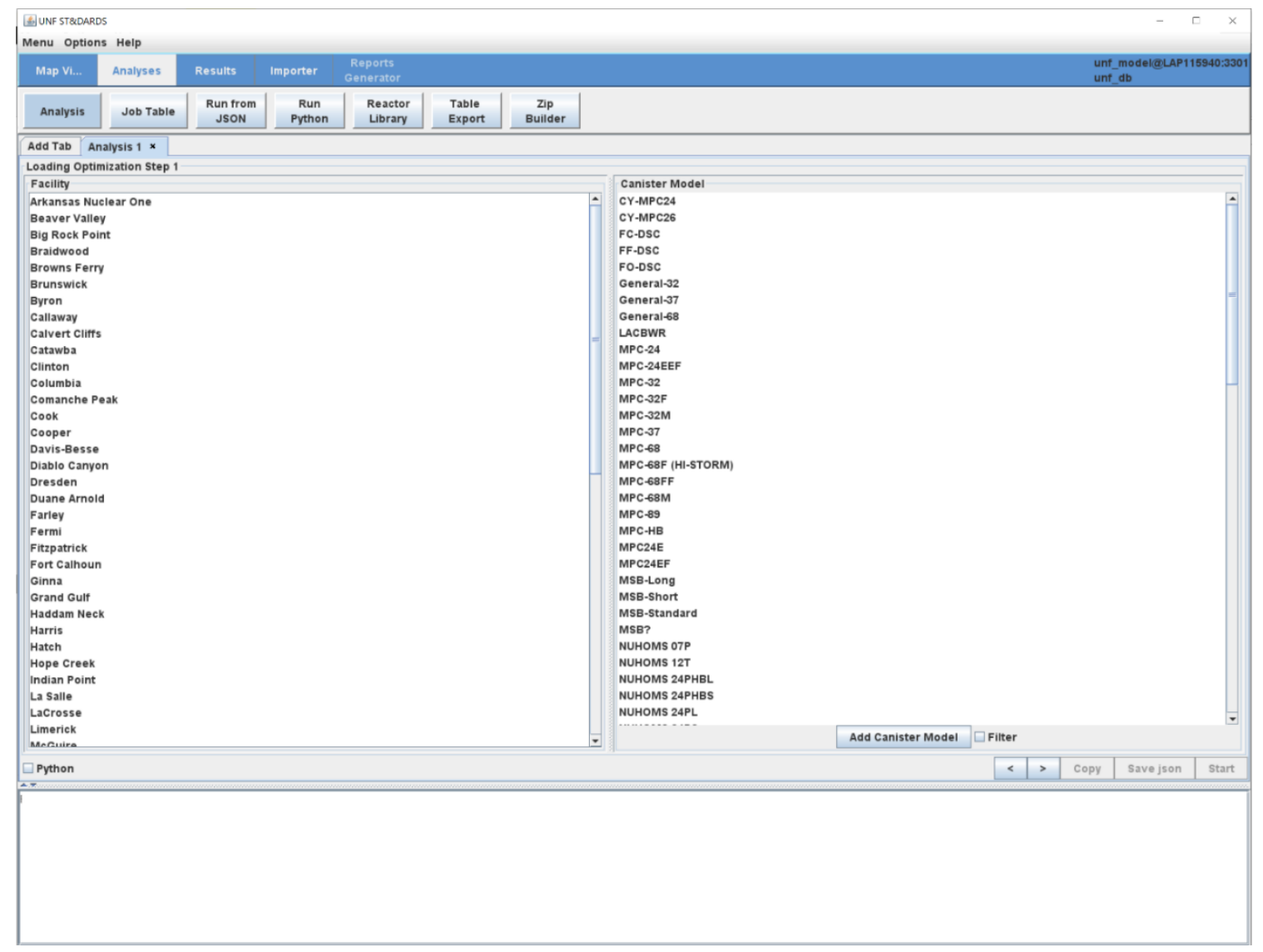

Figure 25. Selecting site and canister model for optimization.

If the user does not wish to use the models listed in the GUI, then a new canister model can be added for optimization by clicking Add Canister Model. This will prompt the user to select the Canister Model Name, as shown in Figure 26. The user clicks on the Next/Forward button to get to next step.

Once the canister model is selected, the user is asked to select the storage and transport overpack models. As in the canister selection, the user can add storage overpack and transport overpack models by clicking on the Add Storage Overpack or Add Transport Overpack button (Figure 27). The user clicks on the Next/Forward button to get to next step. 


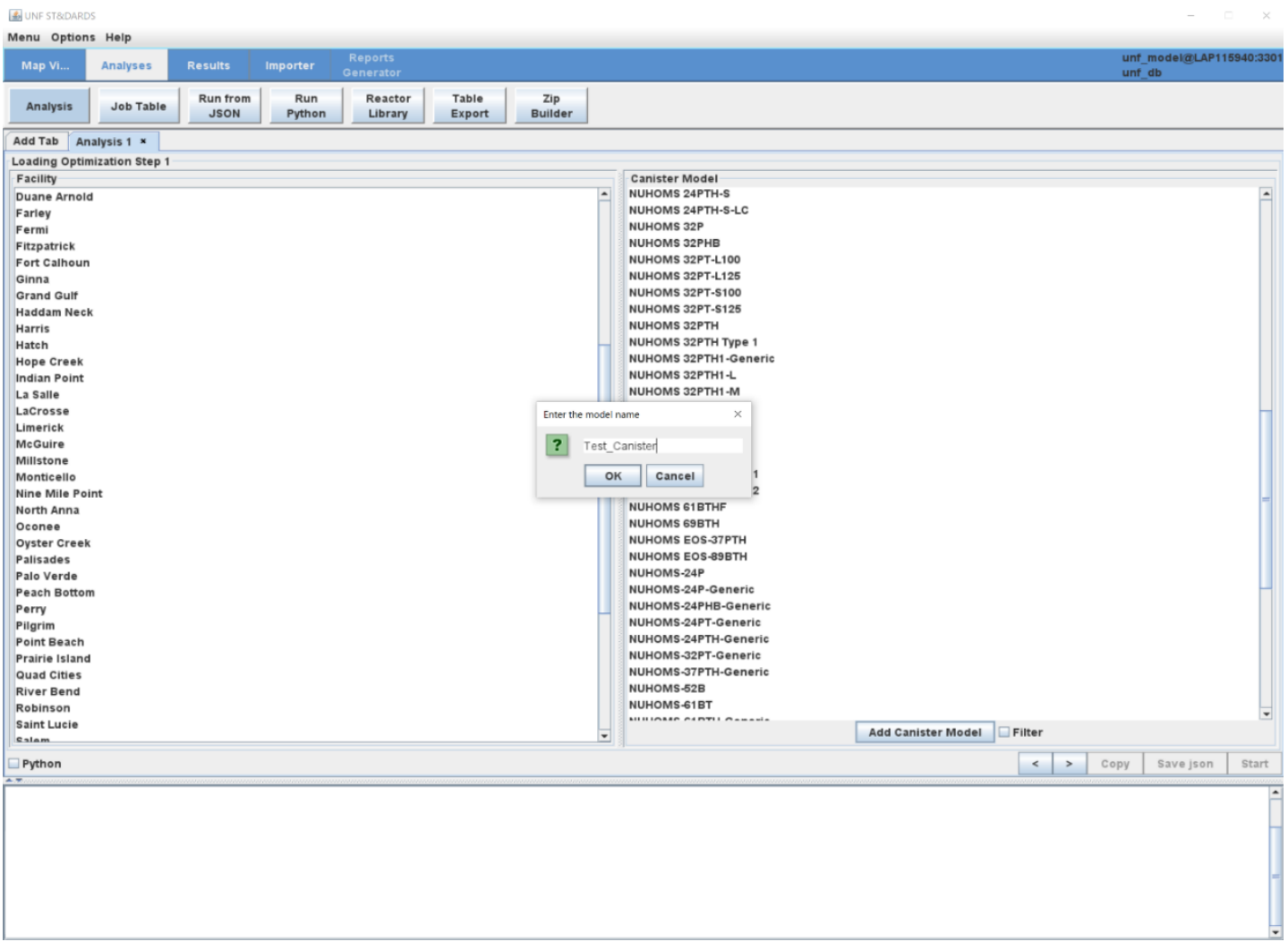

Figure 26. Adding new canister model for optimization.

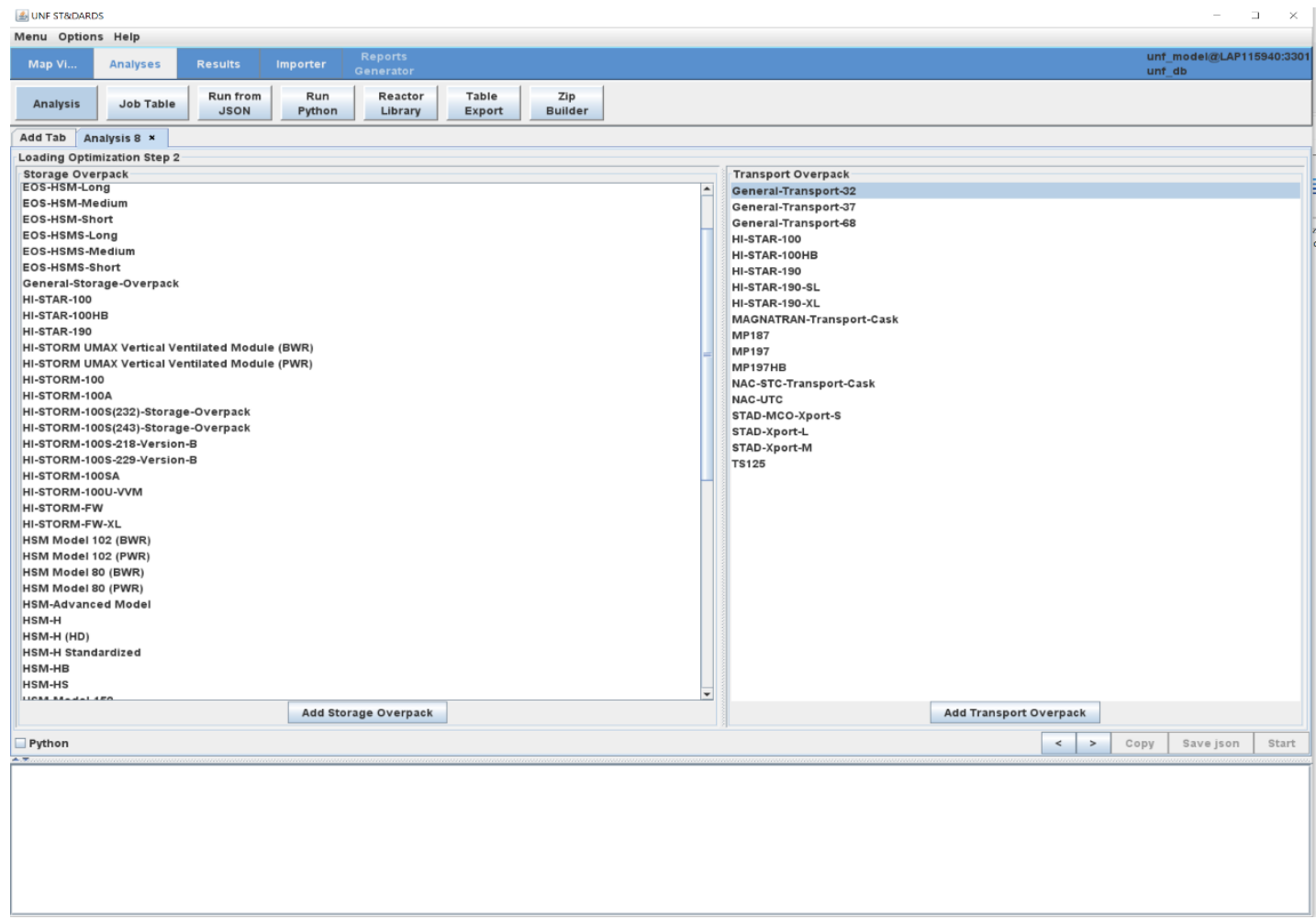

Figure 27. Selecting storage and transport overpack models. 
The user is now prompted to the next step to select heat zones for zone loading. The left side of the GUI allows the user to input the heat zone information for the canister, and the right side displays the canister position map. This step is shown in Figure 28. The user clicks on the Next/Forward button to go to next step.

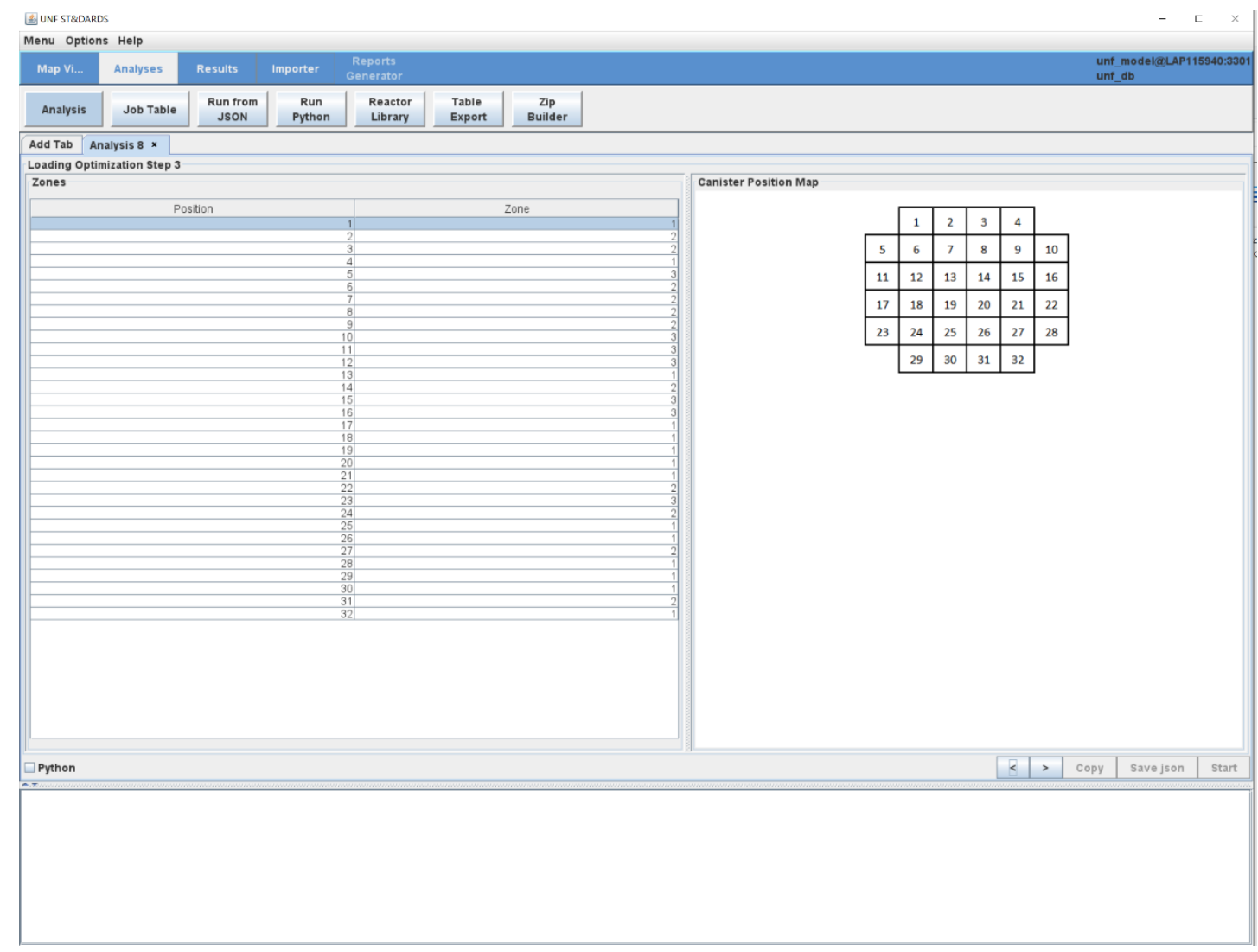

Figure 28. Adding zone loading information to the canister map.

In the next step, the user adds the necessary cask and overpack information as shown in Figure 29. The information is then prepopulated from the database for the available cask types. The user can change the parameters on this step by either loading from the database, loading from a CSV file, or editing the presented information.

If the user selects Load from Database, then a window pops up allowing the user to select from a dropdown menu of the cask models (Figure 29). If the user selects the Load from CSV option, then a pop-up window will prompt the user to select a file from the computer drive (Figure 30). Example CSV files will be added to assist the user with the accepted format for the parameters to be loaded.

The user clicks on the Next/Forward button to get to next step. 


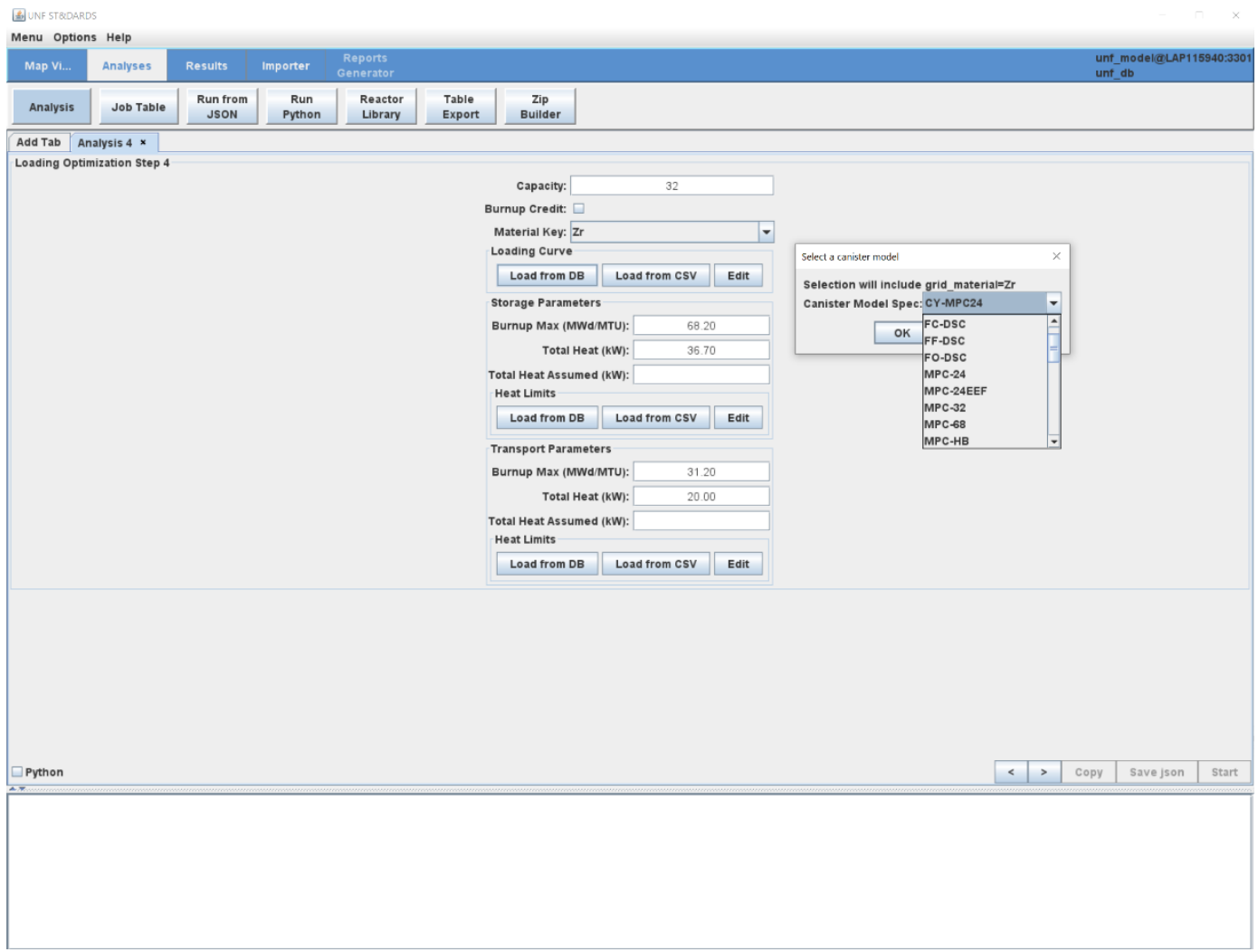

Figure 29. Adding cask and overpack information from the database.

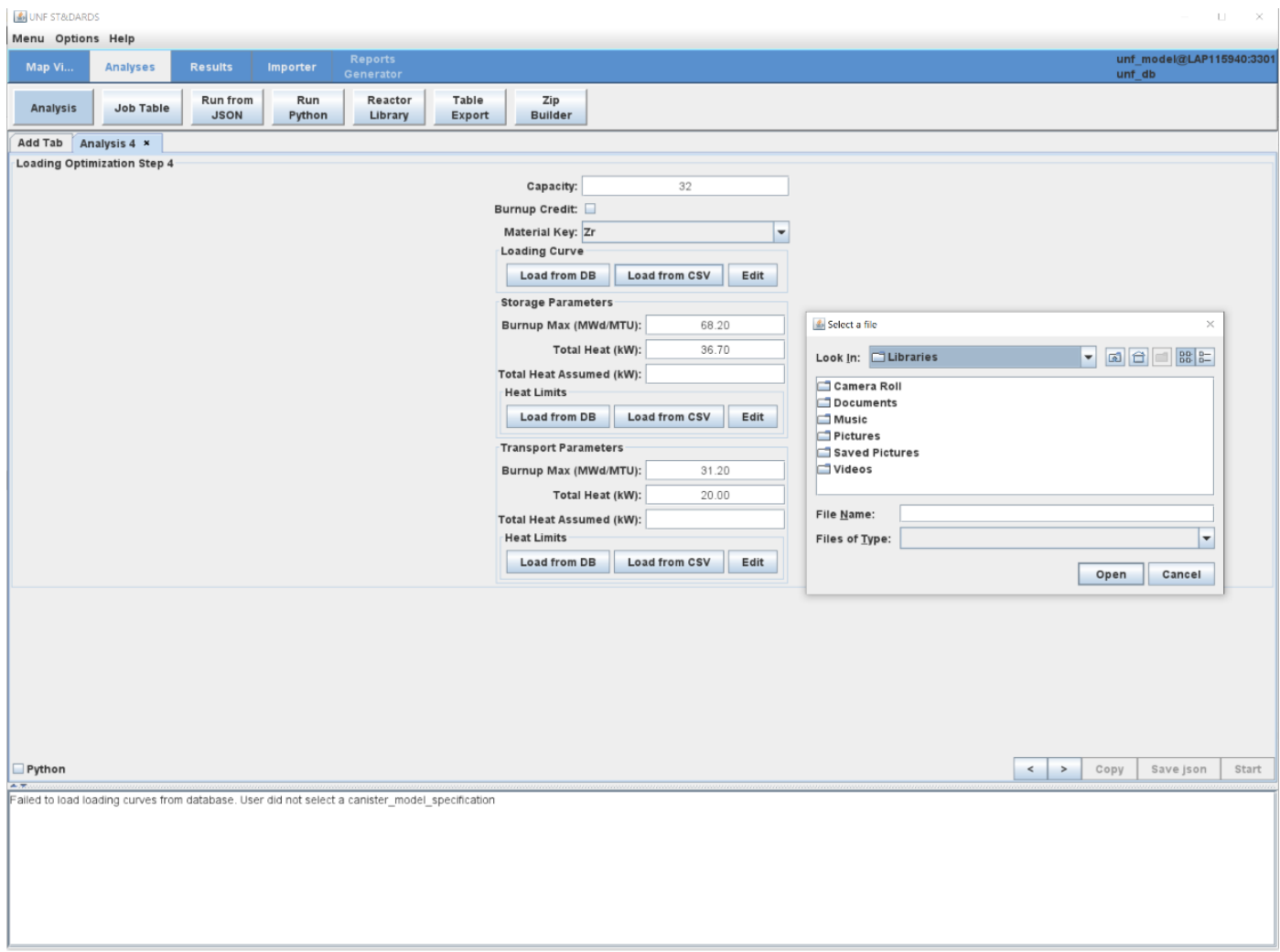


Figure 30. Adding Cask and Overpack Information from the CSV files.

Next, the user is prompted to provide a loading schedule with loading dates and the number of canisters to be loaded for each of the loading dates. As mentioned in Section 2.2.2.1, the user can provide the known loading dates only. Any canister outside the loading dates will be labeled as Not Scheduled in the loading data and the associated plots.

Once the loading schedule is entered, the user can then go back and edit any information previously provided by using the Forward $(<)$ button, copy the information using the Copy button, save the information to a Json file using the Save Json button, or start the optimization process by click on Start (Figure 31).

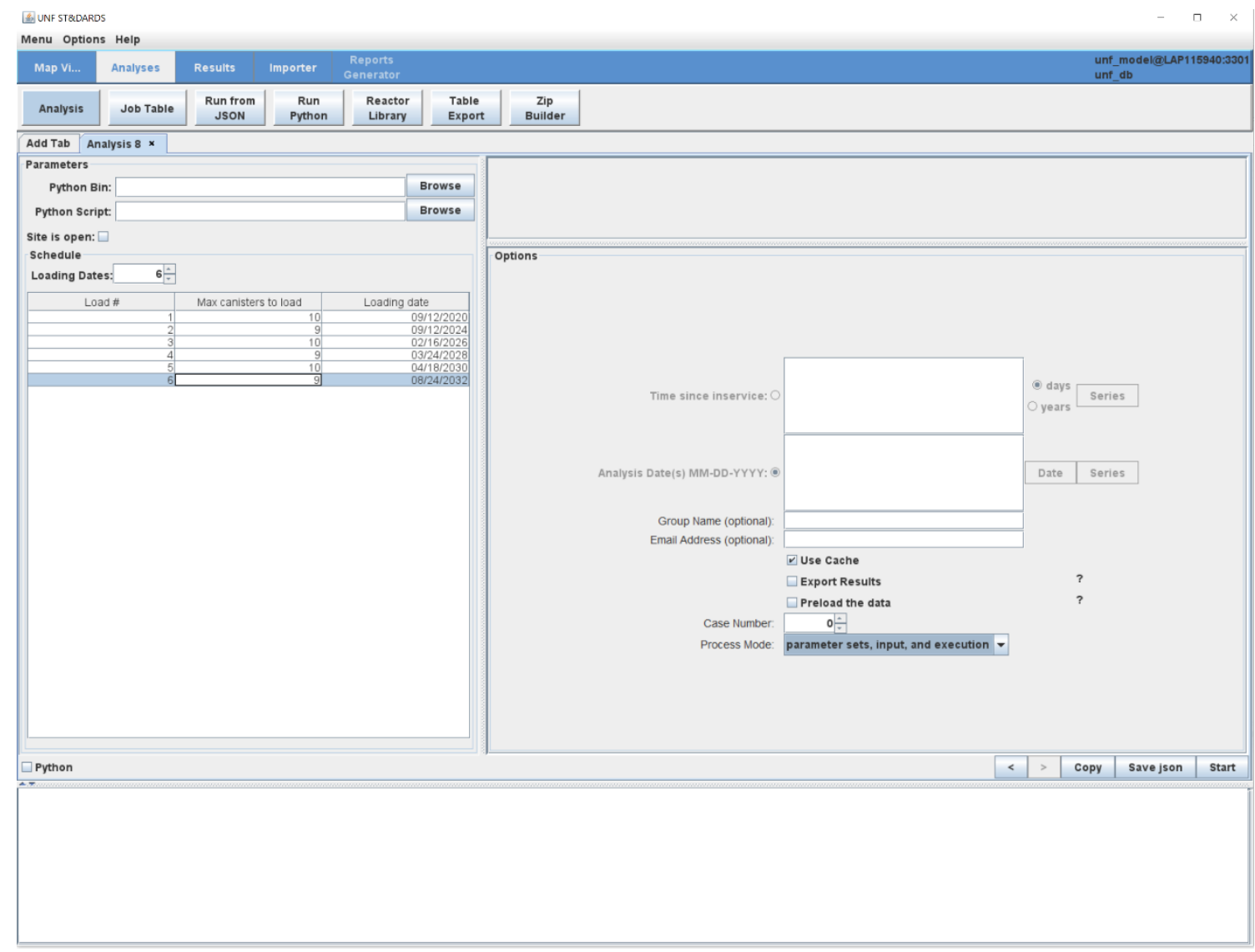

Figure 31. Adding loading information and running optimization.

After the optimization runs, the program will generate csv files and visual plots for the selected solution set as described in Section 2.2.2. Similar set of results will also be generated for the oldest, coldest solution set, for comparison purposes.

\subsubsection{Loading Optimization Case Studies and Results}

This section details the comparison among different solutions generated by the optimization tool and the comparison to a realistic loading scenario.

\subsubsection{Comparisons Among Code Selected Solution Sets}

Performance of the GAMMA-PC optimization tool compared to the oldest coldest packing methodology was tested for three different sites using MPC-32, MPC-37 and MPC-68 cask types [7]. In the study, the solution sets produced by the optimization tool outperformed the oldest, coldest solutions in minimizing 
the parameters of the number of casks needed, the average initial heat loads and the time for the cask to meet the transportation guideline.

While there is no intention to revalidate the work previously performed [7], this report compares the solution sets developed for an entirely different site with the MPC-68 cask type. This comparison was performed to evaluate the effectiveness of the solution picked by the get_sol () function out of a large set of solutions as described in Subsection 2.2.2.1.

For the test site analyzed here with MPC-68 cask type, the optimization tool chose a solution number for the optimized solution and another one for the oldest, coldest solution. The solutions were selected based on the lowest number of casks needed for loading, as shown in Figure 32. It must be noted that the solution IDs for the oldest, coldest solution sets are denoted by negative integers in the code.

Type Solution ID No. of Casks Average Heat Load (kW) Max. Year to Transport

\begin{tabular}{rrrrrr}
\hline $\mathbf{0}$ & Optimized & 1689 & 141 & 15.874307 & 2071 \\
$\mathbf{1}$ & OC & -3 & 141 & 16.763511 & 2077
\end{tabular}

Figure 32. Solutions selected by the optimization tool from the set of solutions.

With a cursory look, it can be seen that for the solutions chosen, the optimized solution had a lower average initial heat load and a sooner overall maximum year as the transport date compared to the oldest, coldest solution.

A detailed look at the distribution of cask heat loads and the maximum year to transport for all the casks within each solution set is shown in Figure 33.
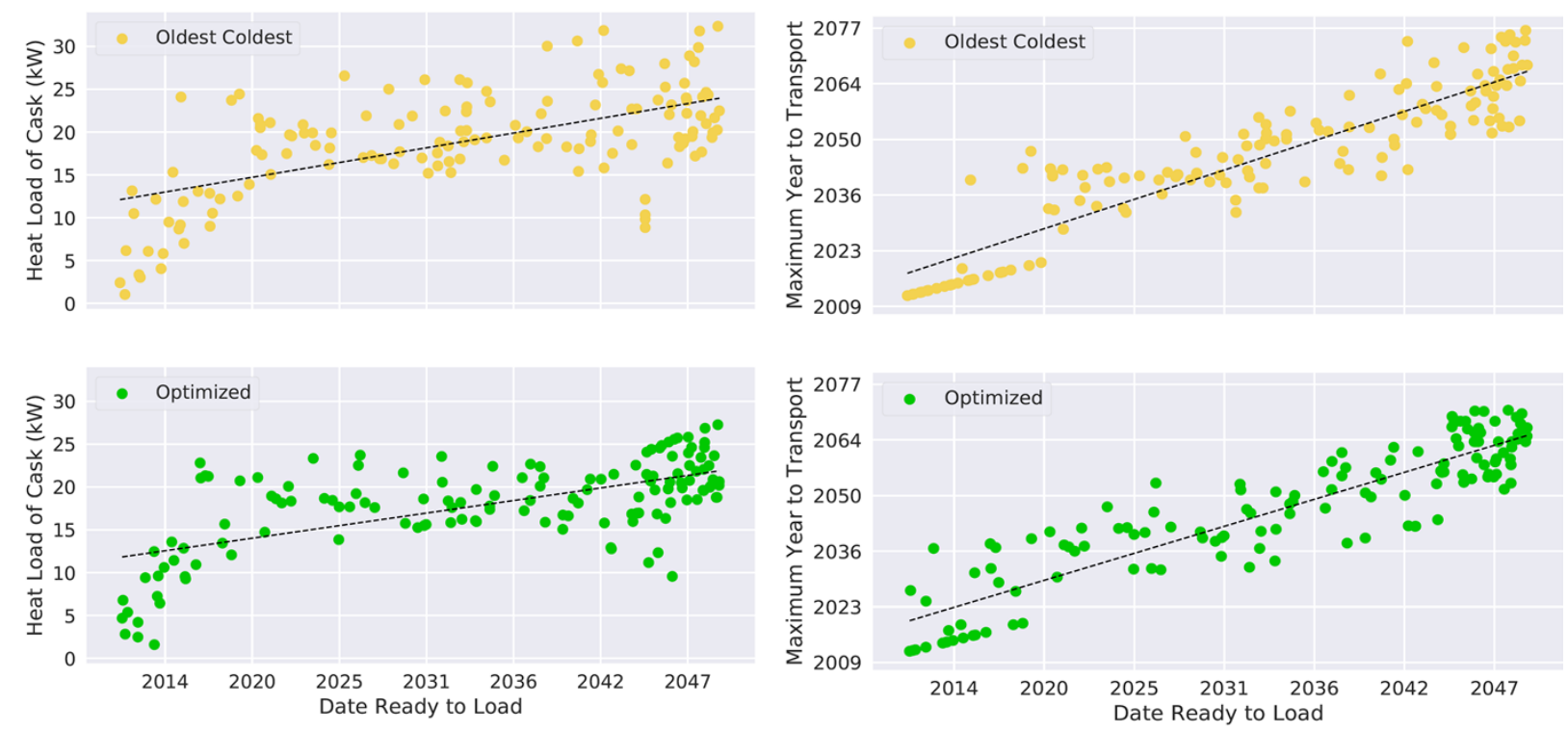

Figure 33. Comparison of optimized and oldest, coldest solutions.

The figure shows that the average heat load of optimized solutions is below $25 \mathrm{~kW}$ for most cases, and the data spread is much tighter towards the trendline. For the oldest, coldest solution set, the distribution of heat loads in the casks is much wider as the timeline progresses. Similarly, the maximum year-totransport spread is more evenly distributed for the optimized solution, yielding a 6-year improvement maximum year to transport, as shown in Figure 32 and Figure 33. 
Since the optimization tool produces a set of near-optimal solutions, another variable of interest is to evaluate how the different optimized solution sets compare against each other. Of the optimized solutions produced, a subset was selected that yielded a variety in the number of casks loaded, maximum year to transport, and average initial heat loads. The different solutions within the optimized solution set are shown in Figure 34.

\begin{tabular}{lrrrrr} 
& Solution ID & No. of Casks & Average Heat Load (kW) & Max. Year to Transport & Rank \\
\hline $\mathbf{0}$ & 1689 & 141 & 15.874307 & 2071 & 1 \\
$\mathbf{1}$ & 2978 & 144 & 15.436033 & 2074 & 1 \\
$\mathbf{2}$ & 4990 & 156 & 14.254356 & 2073 & 1 \\
$\mathbf{3}$ & 5340 & 142 & 15.737903 & 2071 & 1 \\
$\mathbf{4}$ & 5638 & 143 & 15.593596 & 2071 & 1 \\
$\mathbf{5}$ & 5969 & 146 & 15.158356 & 2076 & 1 \\
$\mathbf{6}$ & 6666 & 147 & 14.998815 & 2077 & 1 \\
$\mathbf{7}$ & 7471 & 150 & 14.646244 & 2077 & 1
\end{tabular}

Figure 34. Optimized solutions generated by the tool.

The average decay heat distribution of the casks within the different solutions is shown in Figure 35. 


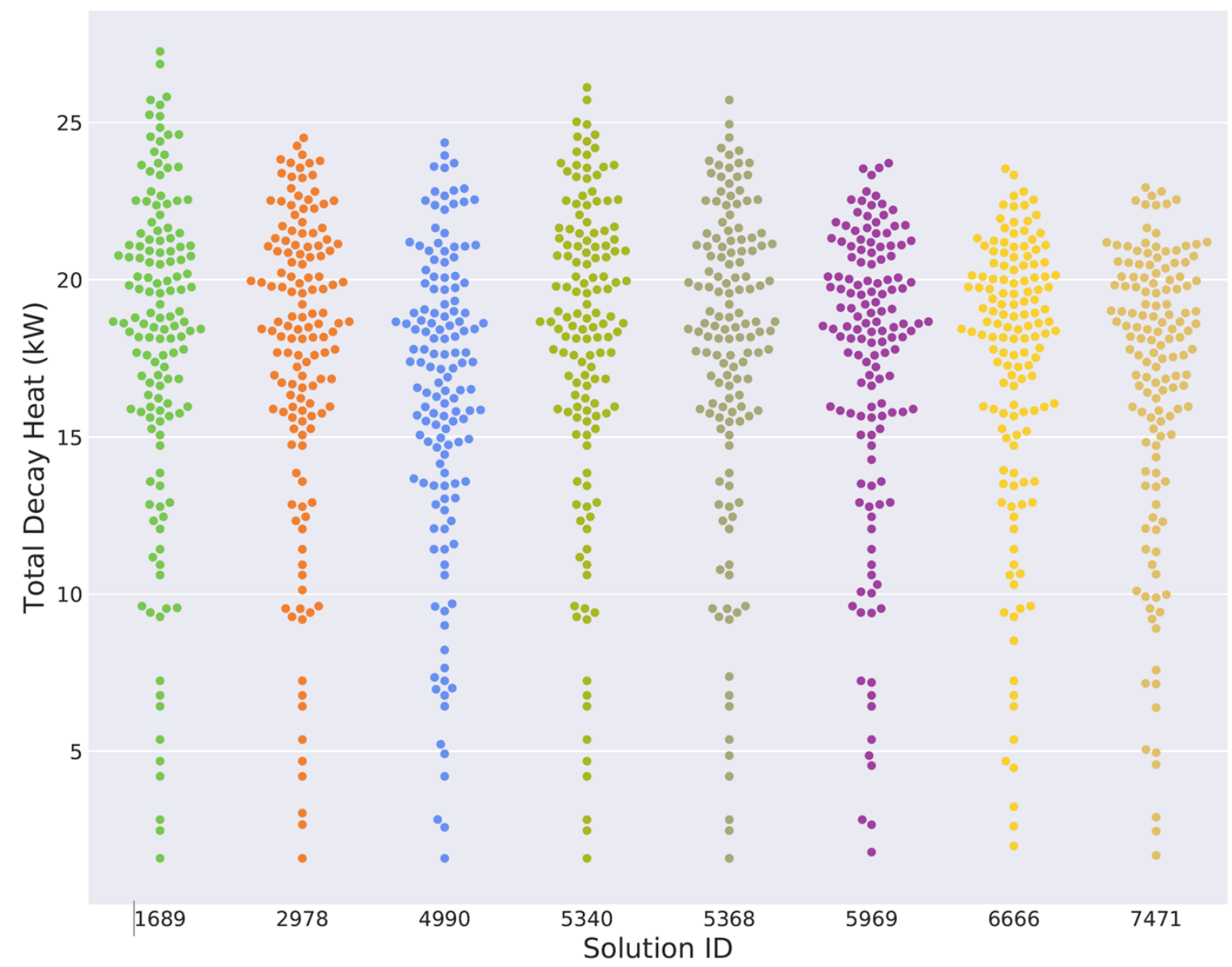

Figure 35. Decay heat distribution of different optimized solutions.

Figure 35 shows that the set of optimized solutions had a very similar distribution pattern. As mentioned previously, all the solution sets generated by the optimization tool meet every single constraint defined within the problem. The tool is currently set to select the solution set with lowest number of casks required among the set of near-optimal solutions.

\subsubsection{Comparison to a Realistic Loading Scenario}

The optimization tool currently generates dry cask loading patterns based on the entire unloaded inventory, including assemblies currently in the pool and the future projected assemblies. However, in real life, the assembly inventory will likely be updated with new reload cycles. This is due to changes in the status of assemblies from projected to actual, along with other design and loading considerations. In a real scenario, the user will likely generate the optimized loading maps for a given loading schedule and then update the assemblies to be loaded to the casks for the first loading in the database. Hence, when the optimization is run for the next loading cycle, it will have a more updated fuel inventory. This will expectedly produce more up-to-date loading patterns. A comparison of such a loading scenario against a once-optimized solution is presented here.

For the study, a site with an MPC-32 cask type was used. This site has 7,240 assemblies in the database, with 2,256 actual assemblies in the pool, and the remaining assemblies are projected for discharge over the lifespan of the site's reactors. The last assembly discharge for this site (in the database) was in 2013.

Two different scenarios were modeled for comparison: 
- For Scenario A, the optimization tool was run with all actual and projected assemblies using a single loading schedule provided by the user

- For Scenario $B$, the optimization tool was run for each loading campaign. After each run, the first set of assemblies from the loading schedule was loaded into the casks and hence was removed from future optimizations. This process was repeated for 5 loading schedules.

Only 5 loading schedules were simulated, since by the end of the fifth loading cycle, 1,600 actual assemblies had been moved to the casks. The loading optimization runs at this point had mostly projected assemblies in the loading plans. In a real-life scenario, however, the projected assembly inventory will decrease with each discharge cycle, and the actual new assemblies will be added to the database.

An 18-month proposed loading schedule was used for the study. The schedule used is shown in Table 1.

Table 1. Loading schedule used in the study

\begin{tabular}{|c|c|}
\hline Date & $\begin{array}{c}\text { Number of canisters } \\
\text { loaded }\end{array}$ \\
\hline $2020-12-15$ & 10 \\
\hline $2022-06-15$ & 10 \\
\hline $2024-12-15$ & 10 \\
\hline $2026-06-15$ & 10 \\
\hline $2027-12-15$ & 10 \\
\hline
\end{tabular}

Figure 36 presents a comparison of the number of canisters available for each load cycle for each date from Table 1, along with the average decay heat for each loading cycle for Scenario A and Scenario B.
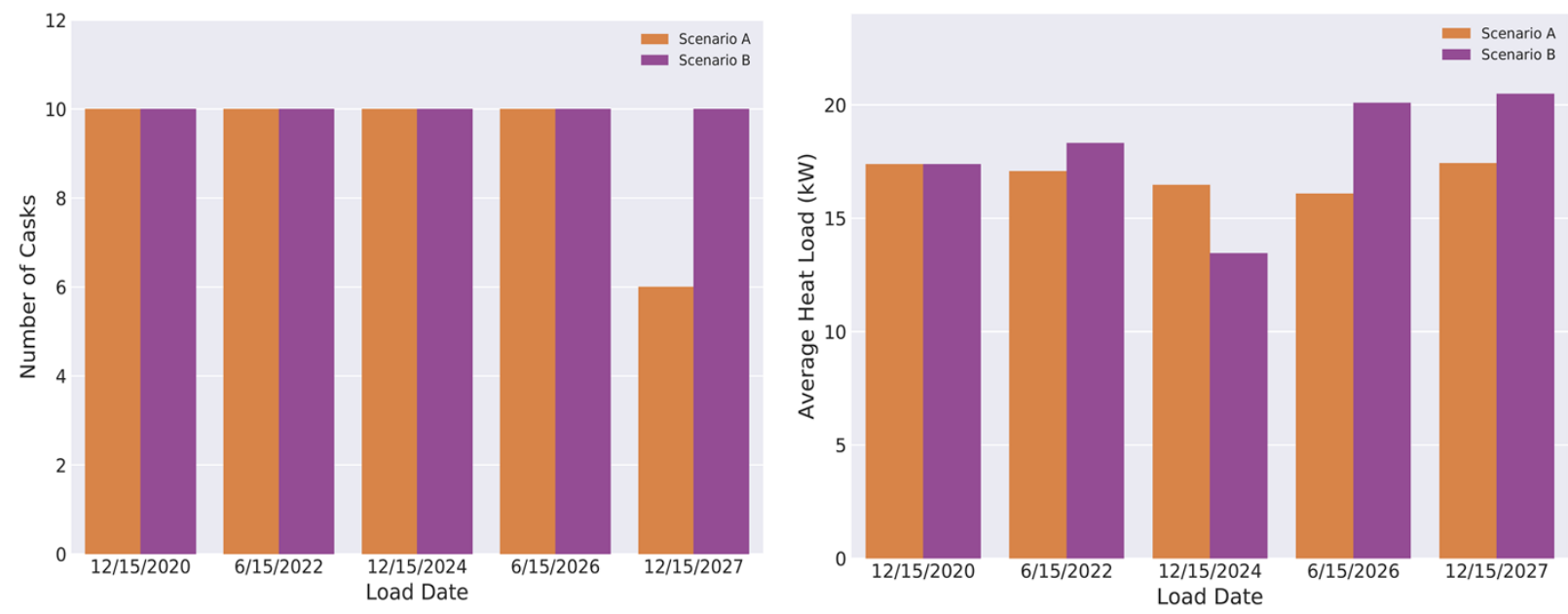

Figure 36. Cask number and average decay heat comparison for the Scenarios A and B.

Note that Scenario A only had 6 casks available to load (Fill Ready Date) for the fifth loading date of $2027 / 12 / 15$. However, Scenario $B$ had enough casks to fill for all loading dates. This is primarily because moving the assemblies to casks after each loading in Scenario B made the problem size smaller and changed the spread of the assemblies to be optimized. The average heat load slightly increased for Scenario $B$. The head load increase is attributed to the fact that the actual assembly inventory was removed after each reload cycle, thus decreasing the ratio of actual-to-projected assemblies. However, in 
a real-life scenario, the assembly inventory would likely be updated with new actual assemblies, resulting in better estimations for the average heat loads.

Furthermore, when analyzing the distribution of total decay heats per canister, it can be seen that Scenario $B$ has a wider distribution and has a much lower Fill Ready Date than Scenario A. The lower Fill Ready Date allowed more canisters to be filled within the user-specified loading schedule. The results are shown in Figure 37 and Figure 38, respectively

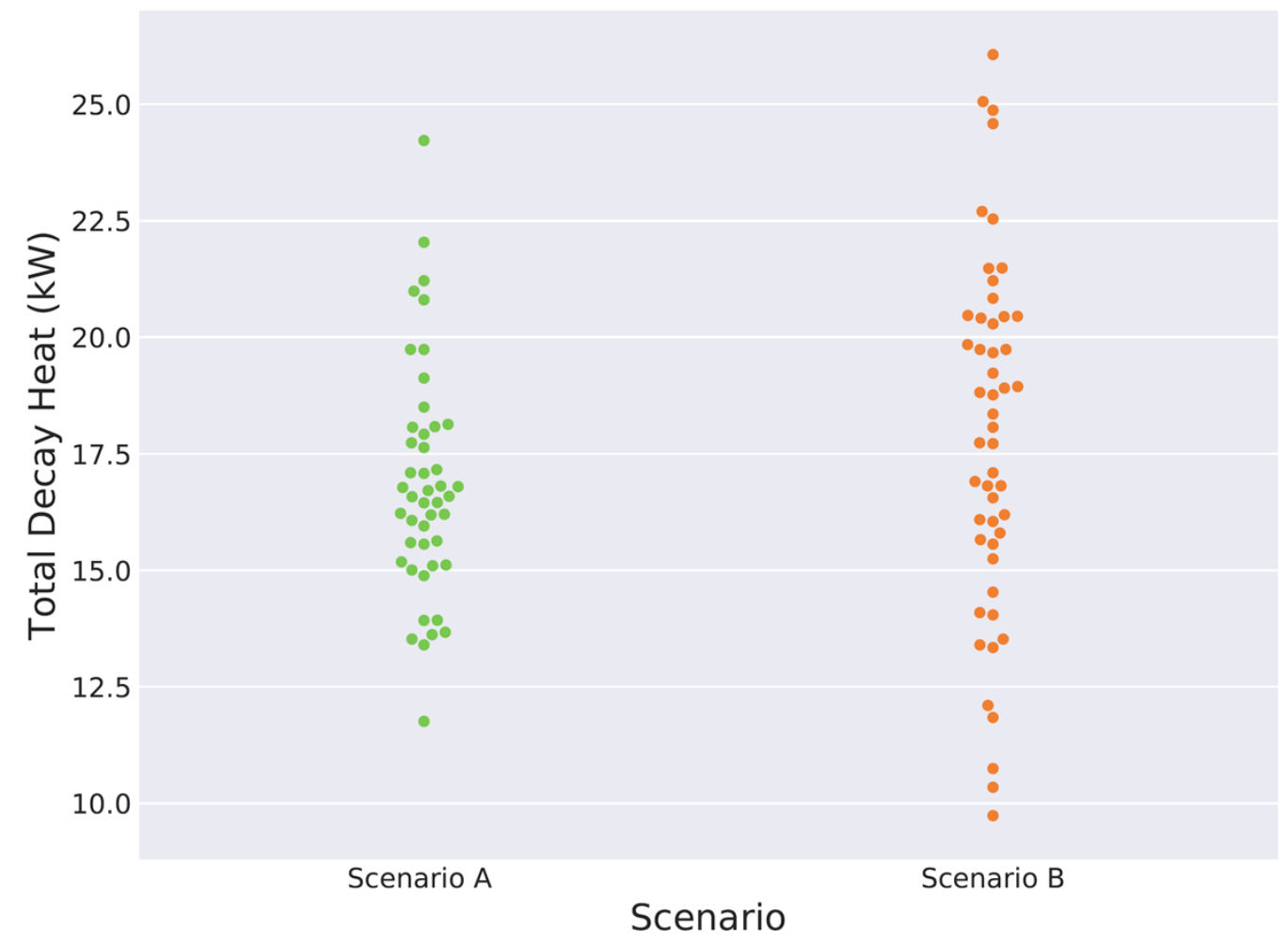

Figure 37. Total decay heat comparison for loading Scenarios A and B. 


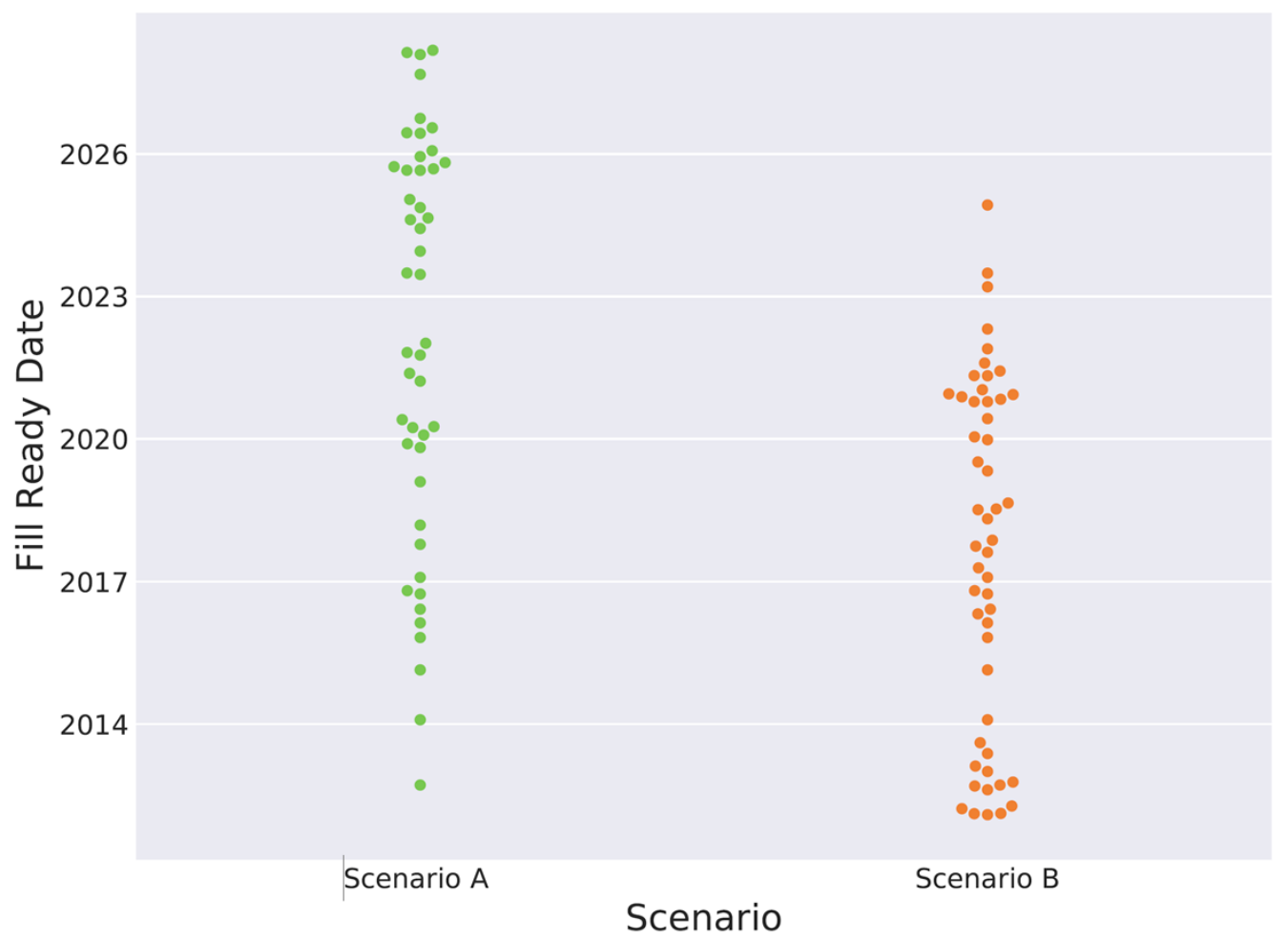

Figure 38. Fill-ready date comparison for loading Scenarios A and B.

Based on the comparisons performed here, Scenario B seemed to perform better overall with the smaller assembly inventory. Since the latest discharge information in the UNF database for this site is updated only until 2013, the optimization tool is expected to provide even better solutions in real applications with the most current assembly information and the updated assembly inventory after each reload cycle.

\subsection{DETAIL AS-LOADED ANALYSIS IN UNF-ST\&DARDS}

The detailed modeling process within UNF-ST\&DARDS uses the most accurate representation of the fuel and operational history possible given the data available to estimate safety margins. The high-fidelity fuel and operational history information are specified for each axial node of each assembly. The combined unique fuel description and unique operational history for each fuel node requires that the roles of the library generation and discharge calculation from the traditional UNF-ST\&DARDS modeling process be combined. Combining these roles significantly increases the number of lattice physics calculations, making it desirable to execute the lattice calculations more quickly. To accomplish this, the SCALE lattice physics code Polaris is used for the discharge concentration portion of the detailed calculations. This detail analysis pipeline, which was developed over last two years and was mainly supported by DOE-NE, can be used to perform best-estimate UNF and related systems characteristics. This is one of the major recent enhancements of UNF-ST\&DARDS.

\subsection{UNF-ST\&DARDS INITIAL COUPLING WITH REACTOR CORE SIMULATORS}

An initial interface has been developed within UNF-ST\&DARDS that allows the user to directly load the discharge isotopic of each node of each discharge assembly if available from a core simulator. The discharge isotopic is then used for downstream decay and criticality analyses. This approach captures all the reactor state point details without modeling them within UNF-ST\&DARDS. 


\subsection{UNF-ST\&DARDS DATA PLOTTING INTERFACE}

An initial data plotting interface has been developed within UNF-ST\&DARDS using Python plotting libraries [10]. The plan is to further develop this generic plotting capability and release this feature with future UNF-ST\&DARDS releases.

A plot option will appear upon right-clicking on a data table, as shown in Figure 39. The plot option panel with self-explanatory options will appear if plot is selected as shown in Figure 40. Various data plots can be generated by selecting plot types and other options. Figure 41 presents an example plot.

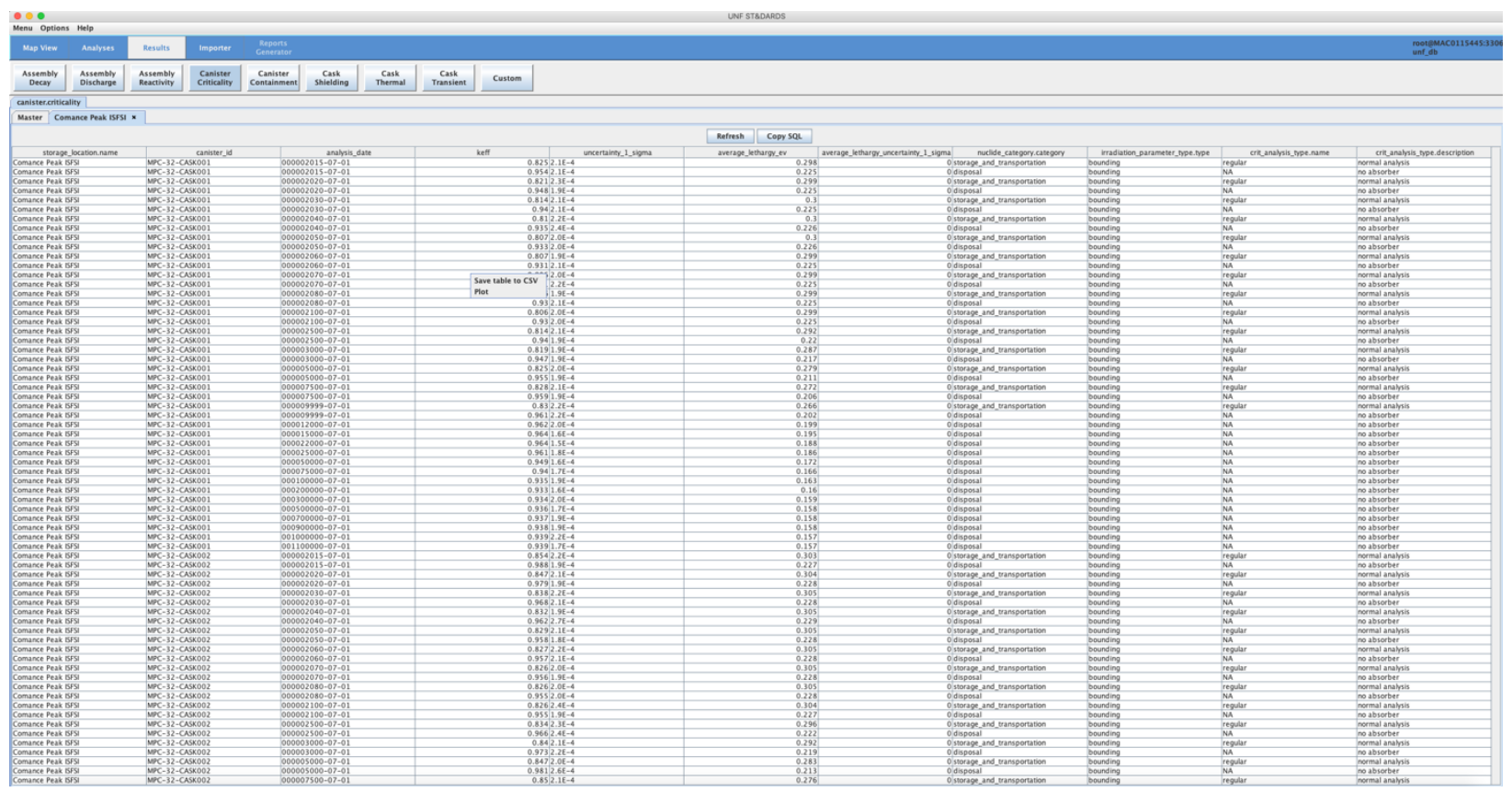

Figure 39. UNF-ST\&DARDS data plot feature. 


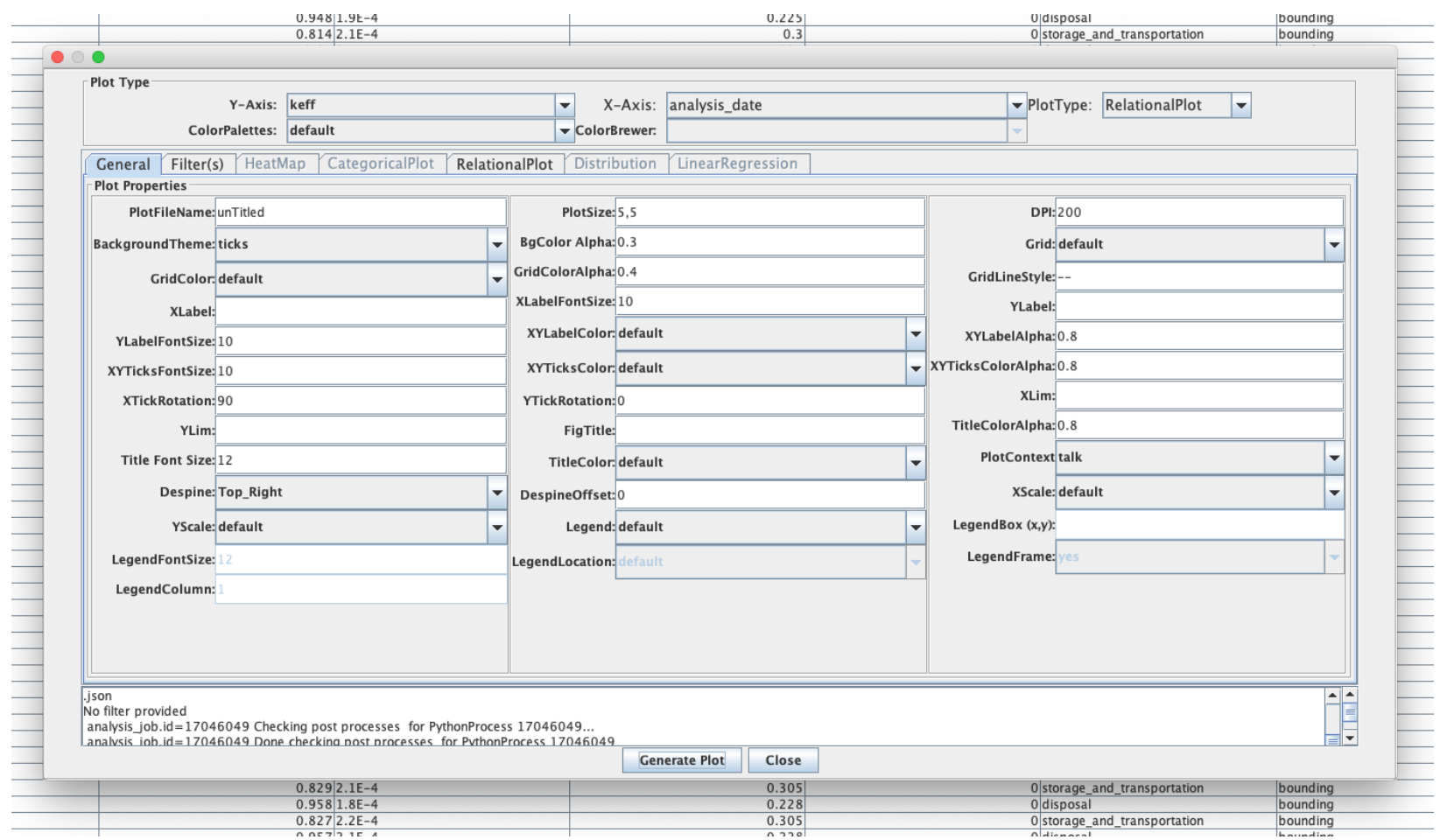

Figure 40. UNF-ST\&DARDS data plot options. 


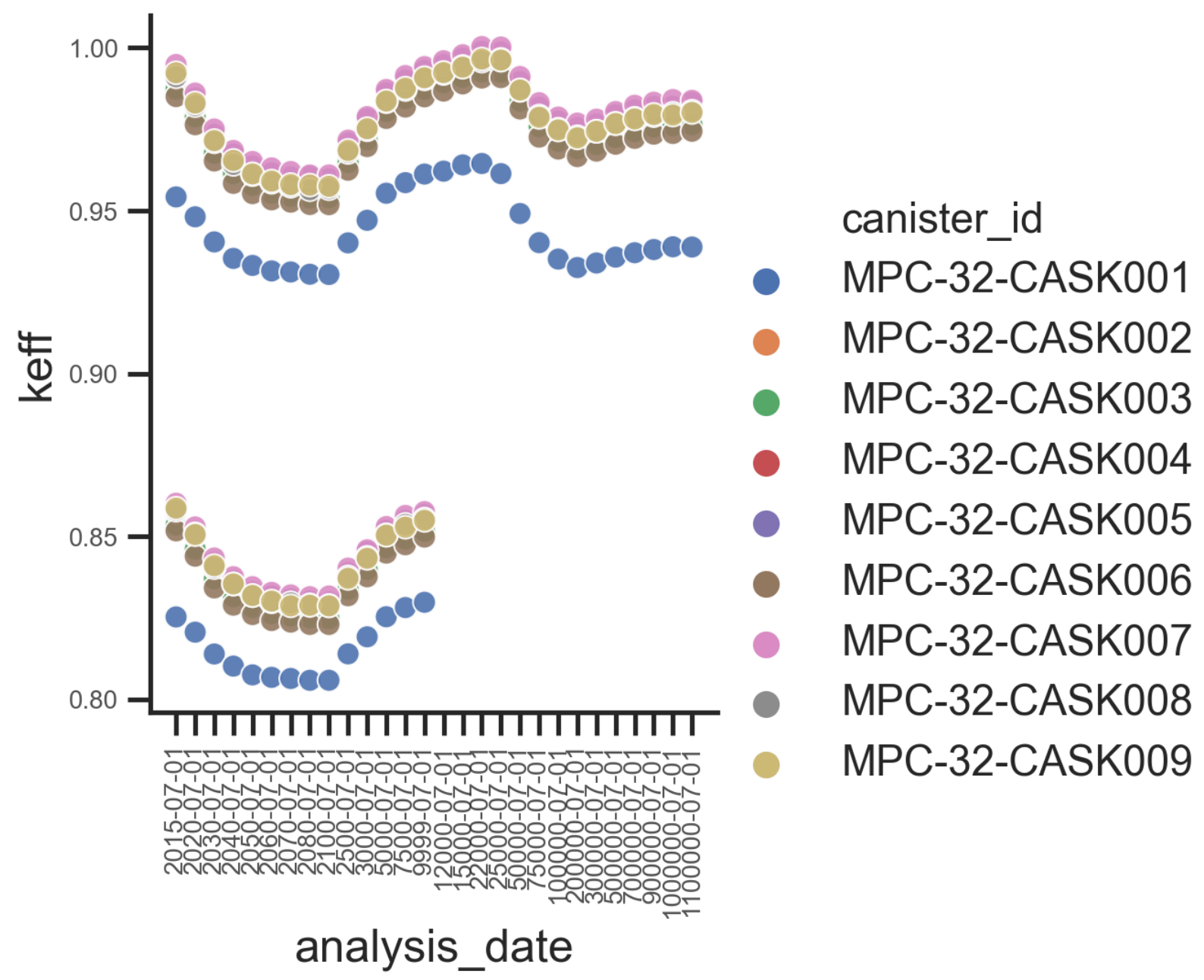

Figure 41. An example plot generated by UNF-ST\&DARDS.

\section{PROGRESS TOWARDS COMMERCIALIZATION}

DOE NE recently granted copyright of UNF-ST\&DARDS Version 4.x to UT-Battelle. UNF-ST\&DARDS is also currently being distributed through ORNL's Radiation Safety Information Computational Center (RSICC), with some restrictions. In last two years, UNF-ST\&DARDS has become the UNF licensing applications review tool for (NRC). UNF-ST\&DARDS is allowing the NRC to perform a more efficient safety review of the licensing applications. Electric Power Research Institute (EPRI) has also shown some interest in UNF-ST\&DARDS. The UNF-ST\&DARDS team provided training to one of the UNF cask vendors and copies of UNF-ST\&DARDS through the RSICC for testing and evaluation purposes. Internationally, the Swiss national cooperative for the disposal of radioactive waste (Nagra) showed interest in using UNF-ST\&DARDS for managing Swiss UNF. The Swedish Nuclear Fuel and Waste Management Co. (SKB) is also using a testing and evaluation version of the UNF-ST\&DARDS for analyzing Swedish UNF inventory. It is envisioned that UNF-ST\&DARDS will be used by nuclear plants for their individual UNF management before the title is transferred to a central UNF management organization(s). The TCF award has been immensely beneficial for improving the UNF-ST\&DARDS TRL. At the beginning of the TCF award, UNF-ST\&DARDS was classified as a component-validated system/subsystem demonstrated in a relevant environment with a TRL of 5-6 
(http://swdev.epri.com/softwaretrls.asp). Currently, UNF-ST\&DARDS can be classified as a system prototype demonstrated in an operational environment with a TRL of 7. The UNF-ST\&DARDS team is currently planning to pursue Phase II TCF award partnering with one of the interested industry partners.

\section{FUTURE IMPROVEMENT}

UNF-ST\&DARDS future improvements include:

- Finalizing the initial dry storage loading algorithm and packaging it with UNFST\&DARDS: The current loading algorithm for UNF-ST\&DARDS is based on decay heat and dose (in terms of burnup, enrichment, and cooling time combinations from CoC) limits. The loading optimization should also consider criticality to support transportation after extended storage and direct disposal of currently loaded canisters. On-the-fly dose analysis can be used to further improve the dry storage loading algorithm.

- On-the-fly dose analysis for as-loaded canisters [11]: This feature can allow on-the-fly dose analysis by changing UNF sources. This can allow industries to perform thousands of dose analyses for various UNF systems with minimal computing resources.

- Allowing users to use the nuclear code of their choice: Currently, UNF-ST\&DARDS uses SCALE for nuclear analysis. Development of an interface that will allow users to plug in their own codes of choice will broadly increase the appeal of UNF-ST\&DARDS as an integrated data and analysis tool.

- Development of capabilities to analyze advanced/next generation fuel cycle: This will allow back-end analysis of various upcoming advanced fuel cycles (e.g., gas-cooled reactor, molten salt reactor).

- Spent nuclear fuel pool analysis capability: Currently, UNF-ST\&DARDS mainly supports various analyses of dry UNF systems. Pool analysis capability will truly make UNF-ST\&DARDS an all-inclusive UNF analysis tool.

\section{CONCLUSION}

The TCF award has been used for developing and supporting various UNF-ST\&DARDS features that have been identified by various user groups as desired features. This report discusses some of the technical advancements of UNF-ST\&DARDS, which were completely and partially supported by the TCF award. The TCF award has also been used for interacting with various nuclear industries and promoting the tool to industries working in the back-end of the nuclear fuel cycle. One of the challenges of commercialization of UNF-ST\&DARDS - and perhaps any nuclear technology - is the slow acceptance process of new technologies/software in the nuclear industry. The UNF-ST\&DARDS team is working with industry partners to show the long-term benefits to industries and society at large for using a UNF management tool like UNF-ST\&DARDS. The TCF Phase I award greatly supported that objective. 


\section{REFERENCES}

1. US NRC, Generic Environmental Impact Statement for Continued Storage of Spent Nuclear Fuel, Office of Nuclear Material Safety and Safeguards, Washington, DC, NUREG-2157, 2014.

2. B. T. Rearden and M. A. Jessee, Eds., SCALE Code System, Oak Ridge National Laboratory ORNL/TM-2005/39, Version 6.2 (2016). Available from RSICC as CCC-834.

3. J. B. Clarity, K. Banerjee, H. K. Liljenfeldt, W. J. Marshall, "As-Loaded Criticality Margin Assessment of Dual-Purpose Canisters Using UNF-ST\&DARDS,” Nuclear Technology, 199(3), 245-275 (2017).

4. UXC Store Fuel, "StoreFUEL and Decommissioning Report," Vol. 21, NO 249, May 2019.

5. J. C. Wagner, J. L. Peterson, D. E. Mueller, J. C. Gehin, A. Worrall et al., Categorization of Used Nuclear Fuel Inventory in Support of a Comprehensive National Nuclear Fuel Cycle Strategy, Oak Ridge National Laboratory, US Department of Energy, ORNL/TM-2012/308, 2012.

6. Improving the Efficiency of the Regulatory Framework for Dry Storage of Spent Nuclear Fuel, Used Fuel Storage and Transportation Issue Screening Form. Issue Number I-16-01, ML16158A049. Available Online: https://www.nrc.gov/docs/ML1615/ML16158A049.pdf [accessed on 09/07/2020].

7. Kristina Yancey Spencer, Adaptive Long-term Optimization of Dry Cask Storage Loading Patterns, Dissertation, Texas A\&M University, December 2017.

8. D. Vinson, Description and Validation of a Revised Tool for Projecting U.S. Commercial Spent Nuclear Fuel Inventory. FCRD-NFST-2015-000534, SRNL-STI-2015-00201, March 31, 2015.

9. K. Banerjee and P. Miller, UNF-ST\&DARDS User Documentation, Release 4.0, Oak Ridge National Laboratory, January 28, 2019.

10. Michael Waskom, "Seaborn: Statistical Data Visualization,”Website: https://seaborn.pydata.org [accessed on 09/17/2020].

11. G. G. Davidson and K. Banerjee, "Toward On-the-Fly Dose Analysis Using the Shift Monte Carlo Code," Trans. Am. Nucl. Soc. 117(1), 1178-1181, Washington, DC (October 2017). 